https://helda.helsinki.fi

Competitive behavior, stress, and gender

\author{
Halko, Marja-Liisa
}

2017-07-04

Halko , M-L \& Sääksvuori , L 2017 , ' Competitive behavior, stress, and gender ' , Journal of Economic Behavior and Organization, vol. 141 , pp. 96-109 . https://doi.org/10.1016/j.jebo.2017.06.014

http://hdl.handle.net/10138/317345

https://doi.org/10.1016/j.jebo.2017.06.014

cc_by_nc_nd

Downloaded from Helda, University of Helsinki institutional repository.

This is an electronic reprint of the original article.

This reprint may differ from the original in pagination and typographic detail.

Please cite the original version. 


\title{
Competitive Behavior, Stress, and Gender
}

(Final draft version of Halko \& Sääksvuori, 2017, Competitive bahavior, stress, and gender, J ournal of Economic Behavior and Organization, 96-109)

\author{
Marja-Liisa Halko ${ }^{\mathrm{a}, \mathrm{b}}$, Lauri Sääksvuori ${ }^{\mathrm{c}, \mathrm{d}}$ \\ a Department of Political and Economic Studies, P.O. Box 17, \\ 00014 University of Helsinki, Finland \\ ${ }^{\mathrm{b}}$ Department of Economics, School of Business, P.O. Box 21240, 00076 Aalto University, Finland \\ ${ }^{\mathrm{c}}$ National Institute for Health and Welfare, Centre for Health and Social Economics, P.O.Box \\ 30, 00271 Helsinki, Finland \\ ${ }^{\mathrm{d}}$ Joint Research Centre, European Commission, Italy \\ Address correspondence to: \\ marja-liisa.halko@helsinki.fi
}

\begin{abstract}
:
This paper investigates whether physiological measures related to chronic and acute stress predict individual differences in willingness to compete. We measure individuals' autonomic nervous system activity in a resting state as well as under non-competitive and competitive incentive schemes using heart rate variability (HRV) measurement. We find that both baseline HRV and competition-induced changes in HRV predict willingness to compete. Notably, we find that women with low baseline HRV, a marker associated with chronic stress exposure, are more likely to choose piece rate incentives over competitive incentives than women with high baseline HRV. We observe that men with large acute HRV response to forced competition are more likely to choose tournament pay over piece rate pay than men with small acute HRV response to competition. Our results suggest that HRV can predict individual differences in willingness to compete, but HRV does not close the gender gap in willingness to compete at the aggregate level.
\end{abstract}

Keywords: Competitiveness, Experiment, Gender, Labour market, Stress

JEL: C91, D01, D03, J16, J24 


\section{Introduction}

We frequently face a decision to compete or withdraw from competition in schools, workplaces and social networks. Various types of rankings and tournaments are frequently used in hiring, promotion and school choice. The prevalence of competitive incentives across our social and economic fabric suggests that individual differences in attitudes towards competition may play a large role in determining many important social and economic outcomes over the human lifespan.

An emerging body of economic research has documented significant relationships between individuals' willingness to compete and important outcomes in life. Research shows that competitiveness in economic laboratory experiments is, for example, positively correlated with a propensity to participate in a competitive high school entrance exam (Zhang, 2012) and to choose more prestigious high-school study tracks (Buser et al., 2014). It has also been shown that incentivized laboratory measures for competitiveness can predict labor market earnings (Buser at al., 2015) and industry choice (Reuben et al., 2015).

At the same time, there is substantial evidence that women are more reluctant to compete than men, even though there often are no gender differences in performance (Niederle and Vesterlund, 2007; Niederle and Vesterlund, 2011; Niederle et al. 2013). Gender differences in competitiveness seem to emerge at an early age (Gneezy and Rustichini, 2004; Glätzle-Rützler and Sutter, 2014) and be stronger in mathrelated tasks than in writing-related tasks (Günther et al., 2009; Dreber et al., 2014). The gender gap in competitiveness is documented across several societies (e.g. Gneezy et al., 2009; Andersen et al., 2013; Almås et al., 2014), while there is also evidence suggesting that men and women compete equally in certain societies and circumstances (Dreber et al., 2011; Cardenas et al., 2012). There is also evidence showing that the typical gender gap observed in many Western societies can be reversed in matrilineal societies (Gneezy et al. 2009).

Despite a growing interest to understand the consequences of individual and gender differences in competitiveness, relative little is known about the underlying psychological and physiological mechanisms that may explain individual differences in competitiveness. Our study aims to contribute to the understanding of human competitiveness by investigating whether physiological measures often related to chronic and acute stress can predict individual differences in competitiveness. 
The objective of our paper is threefold: (i) to measure individuals' autonomic nervous system activity in a resting state as well as under non-competitive and competitive incentives in a real real-effort task (adding up sets of five two-digit numbers), (ii) to investigate whether heart rate variability, a robust biomarker of stress-induced autonomic nervous system activity, can predict individual and gender differences in competitiveness, and (iii) to examine whether the relationship between autonomic nervous system activity and willingness to compete is mediated by self-confidence and risk preferences. ${ }^{1}$

Stress is the body's response to the changes in the environment that create taxing demands. ${ }^{2}$ The stress response is geared to maintain our physiological and mental health in the face of acute stressors that are relatively contained events with limited duration. The acute stress response largely helps healthy individuals to adapt to new challenges and typically does not impose a health burden (Nelson, 2005; Rivers and Josephs, 2010). However, under repeated exposure to unremitting psychological or physiological stress acute stress reactions may progress to chronic stress. Acute and chronic stress reactions are shown to have distinct physiological (McEwen, 2007) and behavioral effects (McEwen, 2012; Kandasamy et al. 2014). Exposure to psychological or physiological stress for a prolonged period may lead to reduced bodily responses to acute stressors by downregulating corticosterone responses during chronic stress (Rich and Romero, 2005). Chronic, but not acute, stress has also been associated with structural changes in the human brain (McEwen, 2007). Overall, the effects of chronic stress on neural, cardiovascular, immunological and reproductive health are morbid (Nelson, 2005; Sapolsky, 2005). Importantly, a number of studies have lately recognized the importance of gender in people's physiological responses to stressful events and experiences (Holt-Lunstad et al., 2001; Tytherleigh et al., 2007).

\footnotetext{
${ }^{1}$ Our interest to investigate the role of self-confidence and risk preferences is motivated by existing literature which has documented significant relationships between different stress measures and economic preferences. For example, Goette et al. (2015) find that acute stress increases competitive confidence among individuals with low trait anxiety scores, whereas acute stress decreases confidence among highly anxious individuals. There is also an increasing number of investigations linking physiological measures of acute and chronic stress to risk preferences (Porcelli and Delgado, 2009; Ceccato et al., 2015).

${ }^{2}$ Many types of stressors, like having to perform in a competitive environment, may lead to a stress response, which is adaptive for coping in the short-term, but may over time have a pathological impact on person's mental and physical well-being. In colloquial language, stress is often used to only describe body's negative reactions to challenges. This practice also often applies to epidemiological work which tries to quantify the overall impact of chronic stress on health outcomes and estimate the costs of work-related stress in certain geographical areas and business sectors. For example, the American Psychological Association (APA, 2009) reports that 55 percent of the employees in the U.S. consider themselves to be less productive at work as a result of work-related stress. In the same vein, according to the APA (2007), 52 percent of the U.S. employees report that they have considered or made a decision about their career such as looking for a new job, declining a promotion or leaving a job based on work-related stress.
} 
In this study, we measure participants' autonomic nervous system activity using heart rate variability (HRV) measurement. HRV is a well-established physiological indicator of stress-induced activation of the autonomic nervous system (Task Force, 1996; Acharya et al., 2006; for a systematic review and metaanalysis assessing HRV as an indicator of stress in healthy adults, see Castaldo et al. 2015). ${ }^{3}$ Low HRV values generally signal high sympathetic (stimulative) nervous system activity and occur during the states of high mental and environmental stress. Low HRV values in a resting state are associated with chronic mental and physical stress (Task Force, 1996; Acharya et al., 2006). ${ }^{4}$ By contrast, high HRV values in a resting state are associated with high parasympathetic (inhibitory) activity of the autonomic nervous system. Thus, high HRV values in a resting state are interpreted as signals for fast physiological recovery and good emotional regulation ability (Task Force, 1996; Acharya et al., 2006). While HRV in a resting state has been interpreted as a proxy of chronic stress, short-term changes in HRV indicate acute engagement of the sympathetic nervous system and do not enable us to assess the adaptiveness of this response.

Baseline HRV and competition-induced HRV change should not be interpreted as direct physiological measures of stress. They are potential proxies for chronic and acute stress. In reality, many physiological responses are determined by a myriad of observable and unobservable personal traits and characteristics that may have physiological, behavioral and socially constructed roots. Prior evidence showing that psychological stress measures are related to HRV does not imply that HRV is always related to experienced stress. ${ }^{5}$

Our paper is related to experimental studies investigating relationships between acute stress exposure, cognitive performance and competitiveness. Angelucci and Cordova (2014) investigate the impact of

\footnotetext{
3 The approaches to investigate the causes and consequences of stress broadly fall into two categories: self-reported questionnaires and physiological measures. The advantage of physiological measurements is that they provide direct, objective and easily quantified measures of the body's physiological stress response. In addition to HRV measurements, galvanic skin conductance measurements are often used to measure acute stress responses. There measurements typically complement each other (Lo and Repin, 2002). Our investigation in this paper is limited to the measurement of HRV. The relative benefits of HRV measurement, arguably, include a better ability to predict certain chronic illnesses and unobtrusive measurement sensors which do not interfere with daily activity in naturally-occurring situations.

${ }^{4}$ A number of empirical investigations have related HRV to multiple physiological and psychological concepts. For example, a number of epidemiological studies suggest that HRV in a resting state serves as an independent predictor of future health outcomes and as a proxy for underlying cardiovascular diseases processes (Dekker et al. 2000; Zulfigar et al., 2010). In addition, resting HRV has been associated at least with effective coping strategies, attention control, generalized anxiety disorder and depression (Appelhans and Luecken, 2007). We note that HRV has been empirically related to a wide variety of physiological and psychological concepts which makes it a relatively non-specific proxy for overlapping stress-related concepts.

${ }^{5}$ For a more profound and general discussion about the challenges of inferring psychological significance from physiological signals, see a paper by Cacioppo and Tassinary (1980).
} 
acute stress on cognitive performance and find that exposure to acute emotional stress may reduce women's performance and earnings compared to men's performance and earnings in a task where participants have to answer multiple-choice questions taken from the SAT. Buckert et al. (2015) investigate whether having to perform in a competitive environment causes acute stress reactions. They find that participants' heart rate and arterial blood pressure are higher when performing under competitive incentives than when performing under non-competitive incentives. However, they do not find any effect on participants' cortisol or testosterone levels.

Buser et al. (2016), Zhang et al. (2016) and Cahlikova et. al (2016) report experiments investigating whether an acute stress response to mandatory competition predicts individuals' willingness to participate in a voluntary competition. They also exogenously manipulate stress levels using a cold pressor task (Buser et al., 2016) and the Trier Social Stress Test (Zhong et al., 2016; Cahlikova et. al 2016) to investigate whether exogenously induced stress affects competitiveness. Buser et al. (2016) find a positive association between a stress response measured as salivary cortisol and competitiveness for women, but not for men. Buser et al. (2016) also find a positive causal effect of acute stress on competitiveness for women, but not for men. Zhong et al. (2016) find that more competitively inclined individuals exhibit stronger acute stress responses to competition than less competitively inclined counterparts. Zhong et al. (2016), however, do not find a causal effect of stress on competitiveness. Cahlikova et al. (2016) find that exogenously induced acute stress reduces willingness to compete both among men and women. They also find that acute stress decreases performance in an arithmetic task for women, but not for men.

Our investigation differs in several important aspects from the related studies. First, we measure individuals' HRV in a resting state which serves as a proxy for chronic stress and enables us to investigate the association between baseline HRV and entry into competitive environments. Second, we measure individuals' HRV throughout the exposure to piece rate and tournament incentives which resolves uncertainty about the adequate number and timing of measurements. Third, HRV is known to be a particularly fast-responding and selective measure of mental stress (Mulder, 1992). Consequently, even relatively short recording of HRV are likely to provide an accurate measurement of cardiovascular and nervous system response to competitive incentives. 


\section{Study design}

This section documents our data collection procedure and describes the variables used to examine our research questions. First, we describe the design of our behavioral experiment. Second, we describe the data collection procedure for the heart rate variability data and document the preprocessing of these data. Third, we summarize other key variables used in the results section.

\subsection{Experimental design}

Our experimental design largely follows the within-subject design developed by Niederle and Vesterlund (2007). The basic task in our experiment is to add up sets of five two-digit numbers for five minutes. Participants solve these tasks individually. The experiment consists of five arithmetic tasks under different incentive schemes (Fig. S1). The compensation scheme in Task 1 is a non-competitive piece rate scheme. Participants receive a fixed payment of 25 eurocents for every correct answer. Importantly, participants do not get any feedback about the performance of other participants before completing all experimental tasks.

The compensation scheme in the second task (Task 2) is based on a tournament between four randomly assigned subjects. The participant who correctly solves the largest number of problems in a group is the winner and earns one euro per correct answer. All other participants earn nothing. In case of a tie, the winner is randomly chosen among the best performers. Before Task 2, participants are informed that the gender composition in the group is mixed.

In Task 3, participants select which of the preceding two compensation schemes shall apply to their future performance. If they choose the tournament scheme, their performance during the Task 3 is compared with the performance of the other group members in Task 2.

In Task 4, participants choose between the piece rate and tournament compensation scheme for the past performance in Task 1. At this stage, participants do not perform the arithmetic task, but decide which incentive scheme shall apply to their past piece rate performance. If they choose the tournament compensation scheme, their performance during Task 1 will be compared with the Task 1 performance of the other group members. If an entering participant has the highest performance, he/she wins the tournament. Task 4 has the same payoff structure as Task 3, but eliminates all aspects of performing in a competitive environment. Consequently, the contrast between Tasks 3 and 4 allows us to examine whether the knowledge of having to perform in a tournament affects the selection of preferred payment 
schemes and whether heart rate variability predicts tournament entry when participants do not have to perform in a competitive environment.

After the fourth task, participants are requested to guess their rank in their group in Task 1 and Task 2. Participants are informed that they will be rewarded with one euro for each correct guess. The reward mechanism is implemented to incentivize participants to state their true beliefs about their ranking.

After the completion of all arithmetic tasks we elicit participants' risk preferences using an incentivized measure for risk aversion developed by Holt and Laury (2002) and a general measure of risk-taking propensity derived from a one-item survey question (Dohmen et al., 2011). We also elicit participants' general willingness to compete using a one-item survey question. At the end of the experiment, participants receive their payment based on their performance in one of the five tasks (Fig. S1). Participants are requested to choose one out of the five cards faced down on their computer screen. The cards are in a random order. The chosen card determines which of the five tasks is selected for payment. The total payment for each participant includes a five euro show-up fee, earnings from one randomly chosen task, earnings from the belief elicitation questions and earnings from the incentivized measure for risk aversion.

The experiment lasted in total about 90 minutes. Participants earned on average $12.28 €(\mathrm{Sd} .=5.32)$. The total number of participants was 80 . There were 39 male and 41 female participants. All groups, apart from one, consisted of two male and two female participants. Participants were healthy young adults (average age: men 28.0 years and women 27.0 years) with no history of heart disease. All participants were non-smokers and free of cardiovascular medication. The complete experimental instructions given to participants are available in the Electronic Supplementary Material.

\subsection{Experimental variables}

Heart rate variability: At the beginning of the experiment, participants are requested to attach a HRV measurement device to their chest. ${ }^{6}$ To reliably measure participants' autonomic nervous system activity at the baseline and during different tasks, there is a five minute quiet period just before the first task and

\footnotetext{
6 Participants attach HRV measurement devices to their chest by themselves (Fig. S2). Attaching these devices is straightforward and does not require any particular skill. The device is easy to place under clothes. Attaching the device to a female body does not substantially differ from attaching the device to a male body.
} 
a five minute quiet period just before every arithmetic task (Niizeki and Saitoh, 2012). During the resting periods, participants are instructed to quietly sit in their cubicles and wait for the experiment to continue.

We use heart rate variability (HRV) as an indicator of stress-induced activation of the autonomic nervous system. HRV has proven to be a reliable method to measure bodily stress for clinical and research purposes (Task Force, 1996; Hynynen et al., 2011; Niizeki and Saitoh, 2012), but has been rarely applied to study economic questions. ${ }^{7}$

To measure our participants' heart rate variability we used the FirstBeat Bodyguard heart rate monitor (www.firstbeat.fi). The device is non-intrusive and attaches directly to the skin with two electrodes (Fig. S2). For the HRV data analysis, we used Kubios HRV 2.0 software (Tarvainen et al., 2014). We identified from the beat-to-beat interval series artifacts that are larger or smaller than 150 milliseconds compared to the local average. We applied then cubic spline interpolation to replace these missing intervals. Finally, the resulting corrected beat-to-beat interval series were visually inspected for potentially remaining outliers. At this stage, we had to exclude three participants from our HRV data set due to technical problems. $^{8}$

We use the Root Mean Square of the Successive Differences (RMSSD) to measure the variation of consecutive beat-to-beat intervals. ${ }^{9}$ We compute for each subject four different RMSSD values: one baseline value and three task-related values. The baseline value is computed using a five-minute long resting period just before Task 1 . The values for task-related RMSSDs are calculated using a five-minute period that matches with the performance period in Task 1, Task 2 and Task 3 . In addition to the absolute RMSSD values, we measure competition-induced changes in heart rate variability using differences in RMSSD between Task 1 (piece rate) and Task 2 (tournament). This competition-induced relative change

\footnotetext{
7 There are only a handful of studies that apply heart rate variability measurement to study economic questions. Falk et al. (2011) study physiological response to perceptions of unfairness and find an inverse relationship between heart rate variability and the degree of fairness. Brandts and Garofalo (2012) examine how the gender composition of an audience impacts decisionmakers' responsibility and heart rate variability. They do not find any relationship between gender composition of the audience and heart rate variability. Dullect et al. (2012) examine the physiological foundations of tax compliance in a laboratory experiment and find that higher tax compliance is associated with lower heart rate variability. Dulleck et al. (2014) discuss the applicability of heart rate variability measurement techniques in economic experiments and illustrate the measurement technique in an Ultimatum Game experiment. There are no prior studies examining the predictive power of HRV on economic decisions.

${ }^{8}$ One participant was excluded from the data set due to a technical problem with the HRV measurement device during the measurement period. In this case, no HRV data were recorded. Two participants were excluded from the data set due to unconceivable noise in the beat-to-beat intervals.

${ }^{9}$ For a detailed computation of the Root Mean Square of the Successive Differences see the Electronic Supplementary Material.
} 
in RMSSD measures individuals' autonomic nervous system response to competitive incentives and is defined as: $:^{10}$

$$
\text { Relative change in } R M S S D=100 *\left(\frac{R M S S D(\operatorname{Task} 2)-R M S S D(\operatorname{Task} 1)}{R M S S D(\operatorname{Task} 1)}\right)
$$

Heart rate: We use participants' heart rate (HR, in beats per minute) as a measure of task engagement. Heart rate reactivity is a commonly used measure of task engagement (e.g. Blascovich et al., 2004). We compute the reactivity scores as a difference between average HR during a task and during the resting period.

Willingness to compete: Participants' choice in Task 3 serves as an incentivized measure for participants' willingness to compete.

Choice of compensation scheme for past piece-rate performance: Participants' choice in Task 4 indicates participants' choice of compensation scheme for past piece-rate performance. This choice provides us a measure to gauge participants' preferences for rank-based remuneration in the absence of having to perform in a competitive environment.

Competition attitude: We use participants' answers to a one-item survey question about their general attitude to competition as a measure for their general willingness to compete. This variable takes values from 0 to 10 , where 0 denotes the lowest willingness to compete and 10 denotes the highest willingness to compete.

Risk attitude: To assess the role of risk aversion on individuals' willingness to compete we use a general risk attitude question (Dohmen et al., 2011) and an incentivized risk measurement technique developed by Holt and Laury (2002). In the general risk attitude question, participants are requested to indicate their general risk taking willingness on a scale from 0 to 10 , where 0 stands for "not willing to take risk" and 10 stands for "completely willing to take risk". The incentivized risk measurement lottery contains ten paired lottery decisions with modest payoffs. Participants have to choose between two options in each of the ten prospects. The break-even point where participants switch from the low risk option to the high

\footnotetext{
${ }^{10}$ We additionally use a complementary definition for competition-induced changes in heart rate variability by normalizing the changes in RMSSD using baseline data instead of Task 1 data. In the results section, we report all results using the definition described in Equation (1). In the Electronic Supplementary Material, we report the basic results using the alternative definition for competition-induced changes in heart rate variability (Table S2).
} 
risk option indicates their degree of risk aversion. The full payoff table for the incentivized risk aversion measure is available in the Electronic Supplementary Material.

Confidence in task performance: We measure participants' confidence in their performance by eliciting their beliefs about their relative performance in Task 1 and Task 2 . The lower the guessed rank $(1=$ the best performing group member), the higher the self-rated confidence on being the best performing member in the group. Conversely, the higher the guessed rank ( $4=$ the worst performing group member), the higher the self-rated confidence on being the worst preforming member in the group.

\section{Results}

This section summarizes our main empirical findings. First, we present the descriptive statistics for the key variables. Second, we examine whether heart rate variability predicts individual differences in tournament participation. Third, we investigate whether accounting for differences in heart rate variability can eliminate the gender gap in competitiveness. Finally, we examine potential behavioral pathways that may mediate the relationship between HRV and competitiveness.

\subsection{Descriptive statistics}

Table 1 presents descriptive statistics for all variables included in this study. ${ }^{11}$ In the piece rate incentive scheme, the average number of correctly solved problems is 9.10 by men and 7.93 by women. In the tournament, the average number of correctly solved problems is 10.38 by men and 9.98 by women. We find no significant gender differences in average performance in any task (Table 1, two-sided t-tests, $\mathrm{p}$ > 0.13). ${ }^{12}$ Overall, both men and women perform significantly better under the tournament incentives than under the piece rate compensation scheme (two-sided paired t-test, for men $\mathrm{p}=0.01$, for women $\mathrm{p}<$ $0.01)$.

\footnotetext{
${ }^{11}$ In the Electronic Supplementary Material, we report the pairwise correlation coefficients between the variables included in the analysis (Tables S8-S10).

${ }^{12}$ Even though there are no statistically significant differences in performance between the men and women, we find that men are on average slightly more likely to win the tournament than women. We assess the probability of winning the tournament by simulation. The procedure and results of the simulation are presented in detail in the Electronic Supplementary Material. We use simulated winning probabilities to assess the economic magnitude of participants' tournament entry decisions and to evaluate the robustness of the results reported in this paper. We find that all reported results are largely robust to controlling for individual winning probabilities instead of performance (Table S1). Fig. S3 in the Electronic Supplementary Material presents the distributions of men's and women's performance in Task 2 and winning probabilities.
} 
Table 1: Descriptive statistics

\begin{tabular}{|c|c|c|c|c|c|c|c|c|}
\hline \multirow[b]{2}{*}{ Variable } & \multirow[b]{2}{*}{ Task } & \multicolumn{2}{|c|}{ Full sample } & \multicolumn{2}{|c|}{ Women } & \multicolumn{2}{|c|}{ Men } & \multirow{2}{*}{$\begin{array}{l}\text { Women } \\
\text { vs. men } \\
\text { P-value }\end{array}$} \\
\hline & & Mean & Sd. & Mean & Sd. & Mean & $\mathrm{Sd}$. & \\
\hline \multirow{3}{*}{ Performance } & Piece rate & 8.50 & 3.43 & 7.93 & 2.71 & 9.10 & 4.01 & 0.127 \\
\hline & Tournament & 10.18 & 3.50 & 9.98 & 2.70 & 10.38 & 4.21 & 0.605 \\
\hline & Own choice & 11.18 & 3.88 & 10.85 & 3.48 & 11.51 & 4.29 & 0.451 \\
\hline Performance change & Task2-Task1 & 1.68 & 2.65 & 2.05 & 2.19 & 1.28 & 3.04 & 0.198 \\
\hline \multirow{4}{*}{$H R V$} & Baseline & 37.22 & 18.70 & 41.98 & 22.83 & 32.59 & 12.16 & 0.027 \\
\hline & Piece rate & 31.71 & 12.23 & 35.41 & 20.65 & 28.11 & 12.31 & 0.063 \\
\hline & Tournament & 31.06 & 12.46 & 35.23 & 21.24 & 26.00 & 11.67 & 0.038 \\
\hline & Own choice & 31.42 & 17.88 & 36.12 & 21.56 & 26.84 & 11.94 & 0.022 \\
\hline \multirow{4}{*}{$H R$} & Baseline & 80.15 & 11.75 & 77.28 & 13.01 & 82.93 & 9.75 & 0.034 \\
\hline & Piece rate & 85.50 & 13.29 & 83.73 & 15.11 & 87.23 & 11.16 & 0.251 \\
\hline & Tournament & 87.43 & 14.88 & 85.15 & 17.54 & 89.64 & 11.55 & 0.187 \\
\hline & Own choice & 86.80 & 14.64 & 84.36 & 17.35 & 89.17 & 11.13 & 0.150 \\
\hline Confidence & & 2.24 & 0.88 & 2.39 & 0.77 & 2.07 & 0.96 & 0.110 \\
\hline Risk attitude $(G)$ & & 4.94 & 2.34 & 4.63 & 2.56 & 5.26 & 2.07 & 0.237 \\
\hline Risk attitude (H\&L) & & 5.29 & 2.04 & 5.32 & 2.27 & 5.26 & 1.83 & 0.912 \\
\hline Competition attitude & & 5.76 & 2.75 & 5.51 & 2.84 & 6.03 & 2.67 & 0.408 \\
\hline Willingness to compete & & 0.64 & 0.47 & 0.54 & 0.44 & 0.74 & 0.50 & $0.066^{\eta}$ \\
\hline
\end{tabular}

Table summarizes descriptive statistics for variables measured in the experiment in the full sample and for men and women separately. The first column displays the name of the variable. Risk attitude $(\mathrm{G})=$ general risk attitude, Risk attitude $(H \& L)=$ risk attitude measured using the incentivized price list developed by Holt and Laury (2002). The last column reports p-value testing whether there is a significant difference between men and women. ${ }^{\delta} \mathrm{P}$-value for twosided t-tests, " $\mathrm{p}$-value for Fisher's exact test.

Table 1 shows that participants exhibit lower heart rate variability during the arithmetic tasks than during the baseline measurement (paired two-sided t-tests for mean baseline RMSSD and Task 1 or Task 2 related RMSSD: $\mathrm{p}<0.01$ for both genders). Thus, we observe that HRV decreases as a response to the arithmetic task. ${ }^{13}$ However, we do not observe significant differences in participants' HRV when moving

\footnotetext{
${ }^{13}$ Participants' HRV response the arithmetic task in our experiment parallels athletes' HRV response to precompetitive anxiety (Blásquez et al. (2009). Our results demonstrate that simple experimental tasks conducted under piece-rate and
} 
from piece rate incentives to a forced tournament (paired two-sided t-tests for Task 1 vs. Task 2 related RMSSD: men, $\mathrm{p}=0.126$; women, $\mathrm{p}=0.856) .{ }^{14} \mathrm{We}$ find that women on average exhibit higher baseline heart rate variability than men. ${ }^{15}$ This effect is statistically significant during the baseline measurement and all arithmetic tasks (Table 1).

Table 1 reports participants' heart rate (HR, in beats per minute) during the baseline measurement and arithmetic tasks. We use heart rate reactivity as a proxy for task engagement. We are particularly interested in heart rate reactivity between the baseline measurement and Task 1 which introduces the arithmetic summation task for the first time. We find that participants' heart rate is significantly higher during all arithmetic tasks compared to the baseline (two-sided t-tests against zero, Task 1 mean difference $=5.29(\mathrm{bpm}), \mathrm{p}<0.001$; Task 2 mean difference $=7.19(\mathrm{bpm}), \mathrm{p}<0.001$, Task 3 mean difference $=6.65(\mathrm{bpm}), \mathrm{p}<0.001)$. We find no differences in heart rate reactivity between the men and women $(p>0.14)$. These observations, together with the fact that almost all participants improve their performance when moving from piece rate to tournament incentives, suggest that participants were on average adequately engaged during the experimental tasks.

We find that participants are on average overconfident about their rank in the tournament. Their mean rank guess of 2.2 is significantly more optimistic than the true average rank of 2.5 (two-sided t-test against the true average rank of $2.5, \mathrm{p}=0.004)$. We do not find significant gender differences in risk or competition attitudes.

\footnotetext{
tournament incentives in a laboratory environment can induce a HRV response which is qualitatively similar to the HRV response of individuals preparing to compete in a natural environment

${ }^{14}$ The fact that there is a significant decrease in HRV when moving from the resting state to piece rate incentives shows that participants' heart rate variability responds to the solving of arithmetic problems under piece rate incentives. The fact that there is no significant decrease in HRV when moving from the piece rate to the forced tournament suggests that participants' heart rate variability does not respond to the introduction of tournament incentives per se. However, the lack of response to competitive incentives may also be due to the order of piece rate and tournament incentives. The HRV time series data collected throughout the experiment show that participants' HRV recovers towards the baseline during the 5 minutes recovery period between the piece rate task and tournament task, but the baseline HRV is still on average lower at the beginning of Task 2 than Task 1. The placebo regressions reported in the Electronic Supplementary Material (Table S3) show that the change in HRV when moving from the baseline to the piece rate is not associated with participants' tournament entry decisions.

${ }^{15}$ Medical and epidemiological research has reported references ranges and average values for short time (5-minute) HRV values in different gender and age groups. A comparison between the reference values and values recorded in our study is provided in the Electronic Supplementary Material. In addition, figure S6 in the Electronic Supplementary Material presents the distributions of baseline RMMSDs by gender and the distributions of competition-induced changes in HRV by gender.
} 
Finally, Table 1 shows that 54 percent of the women and 74 percent of the men choose the tournament compensation scheme (Fisher's exact test, $\mathrm{p}$-value $=0.066$ ) ${ }^{16} \mathrm{We}$ find that the gender gap in entry increases with performance (Fig. S4A). Gender difference in the tournament entry is significant in the group of high-performing participants (performance in Task $2 \geq$ median, Fisher exact test, $\mathrm{p}=0.044$ ), but not significant in the group of low-performing participants (performance in Task $2<$ median, Fisher exact test, $\mathrm{p}=0.505){ }^{17}$

\subsection{Heart rate variability and willingness to compete}

In the following, we investigate whether baseline HRV and competition-induced changes in HRV predict willingness to compete in Task 3. Our probit regression estimates in Table 2 show that baseline HRV is positively associated with participants' tournament entry decisions. This result is robust to controlling for gender, performance, competition-induced changes in HRV, confidence, risk and competition attitudes, and performance change between Task 1 and Task 2. Ceteris paribus, one unit increase in baseline RMMSD is associated with a 0.7 percentage points increase in the likelihood of tournament entry. A one standard deviation increase in baseline HRV (in model 5) is associated with 16.0 percentage points increase in the probability of tournament entry. ${ }^{18} \mathrm{We}$ summarize our observations as follows:

Result 1: Baseline heart rate variability is positively associated with participants' willingness to participate in a tournament.

\footnotetext{
${ }^{16}$ Our results show that the proportion of men choosing the tournament compensation scheme in Task 3 equals the previously reported proportions in other Western subject pools. However, the proportion of women choosing the tournament compensation scheme is slightly higher in our experiment than in many previously reported experiments. For example, see evidence for university students in the U.S. (Niederle and Vesterlund, 2007, Niederle et al., 2013), for university students in Germany (Müller and Schwieren, 2012) and for high-school students among two different ethnic groups and the Han Chinese in China (Zhang, 2014).

${ }^{17}$ In the full sample, the odds of a man choosing the tournament in Task3 are 2.50 [95\% CI: 0.973 - 6.445] times greater than for a woman. In the group of high performing participants (performance in Task $2 \geq$ median), the odds of a man choosing the tournament is 5.40 [95\% CI: $1.008-28.928$ ] times greater than for a woman.

${ }^{18}$ We use throughout the results section 5 minutes long resting state heart rate variability as a measure of baseline HRV. To assess the robustness of our results, we compare the 5 minutes long resting period values with HRV values measured throughout the initial resting state and exposure to experimental tasks (approximately 60 minutes). The average HRV over the 60 minutes measurement period serves as an alternative measure of baseline HRV. We find that the two baseline measures are highly correlated (pairwise correlation $=0.858, \mathrm{p}<0.01$ ). We also re-estimate the regression models reported in Table 2 using the 60 minutes long HRV values instead of 5 minutes long resting period values and find that the reported results are robust to this alternative measure of baseline HRV (Table S4).
} 
Table 2: Probit models on Task-3 payment scheme choice $(1=$ tournament, $0=$ piece rate $)$

\begin{tabular}{|c|c|c|c|c|c|}
\hline & (1) & (2) & (3) & (4) & (5) \\
\hline Woman & $\begin{array}{c}-0.202 * * \\
(0.092)\end{array}$ & $\begin{array}{c}-0.237 * * * \\
(0.090)\end{array}$ & $\begin{array}{l}-0.178^{*} \\
(0.091)\end{array}$ & $\begin{array}{c}-0.241 * * * \\
(0.086)\end{array}$ & $\begin{array}{c}-0.143 * \\
(0.074)\end{array}$ \\
\hline Performance & $\begin{array}{c}0.048 * * * \\
(0.013)\end{array}$ & $\begin{array}{c}0.049 * * * \\
(0.013)\end{array}$ & $\begin{array}{c}0.038 * * * \\
(0.014)\end{array}$ & $\begin{array}{c}0.040 * * * \\
(0.013)\end{array}$ & $\begin{array}{c}0.016 \\
(0.014)\end{array}$ \\
\hline Baseline RMSSD & & $\begin{array}{c}0.006 * * \\
(0.003)\end{array}$ & & $\begin{array}{c}0.007 * * * \\
(0.003)\end{array}$ & $\begin{array}{c}0.007 * * * \\
(0.002)\end{array}$ \\
\hline RMSSD change & & & $\begin{array}{c}-0.006 * * \\
(0.003)\end{array}$ & $\begin{array}{c}-0.006 * * * \\
(0.003)\end{array}$ & $\begin{array}{c}-0.006 * * * \\
(0.002)\end{array}$ \\
\hline Confidence & & & & & $\begin{array}{c}-0.184 * * * \\
(0.045)\end{array}$ \\
\hline Risk attitude & & & & & $\begin{array}{c}0.040 * * \\
(0.016)\end{array}$ \\
\hline Competition attitude & & & & & $\begin{array}{c}0.007 \\
(0.013)\end{array}$ \\
\hline Performance change & & & & & $\begin{array}{c}-0.157 * \\
(0.092)\end{array}$ \\
\hline Observations & 80 & 77 & 77 & 77 & 77 \\
\hline Pseudo $\mathrm{R}^{2}$ & 0.137 & 0.186 & 0.168 & 0.240 & 0.486 \\
\hline Correctly classified (\%) & 66.25 & 76.62 & 67.53 & 71.43 & 87.01 \\
\hline
\end{tabular}

Table reports average marginal effects with standard errors in parentheses. Woman is a dummy variable, where women $=1$ and men $=0$. Performance denotes the number of correctly solved arithmetic problems in Task 2 . RMSSD change denotes competition-induced change in heart rate variability measured in normalized RMSSD values. Confidence denotes participants' guesses about their rank among the group members in Task 2 and takes values from 1 to 4 , where lower values indicate higher self-confidence. Risk attitude denotes participants' answer to a general risk question on a scale from 1 to 10 where lower values indicate lower willingness to take risks. Competition attitude denotes participants' answer to a general competition attitude question on a scale from 1 to 10 where lower values indicate lower willingness to compete. Performance change denotes the difference in the number of correctly solved arithmetic problems between Tasks 2 and 1. Positive values indicate greater performance in the tournament compensation scheme than in the piece rate. $* * *$ significant at $\mathrm{p}<0.01$, **significant at $\mathrm{p}<0.05$, *significant at $\mathrm{p}<0.1$.

Table 2 shows that competition-induced change in HRV is negatively associated with tournament entry decisions. In other words, individuals who experience stronger decrease in HRV are more likely to participate in the tournament. The effect is statistically significant and robust to controlling for gender, performance, baseline HRV, confidence, risk and competition attitudes and competition-induced performance change. ${ }^{19} \mathrm{~A}$ one standard deviation increase in competition-induced HRV change (in model

\footnotetext{
${ }^{19} \mathrm{We}$ also estimate the model specification (5) using a different measure for risk attitudes (Holt \& Laury, 2002) and find that the results reported in Table 2 are robust to using this alternative risk attitude measure (Table S5).
} 
5) is associated with 11.5 percentage points decrease in the probability of tournament entry. We summarize these observations as follows:

Result 2: Competition-induced change in heart rate variability is negatively associated with participants' willingness to participate in a tournament.

\subsection{Heart rate variability and tournament entry among women and men}

Our results 1 and 2 suggest that baseline heart rate variability and competition-induced changes in heart rate variability are associated with a voluntary entry into a competitive environment. In the following, we assess the consistency of these results among men and women.
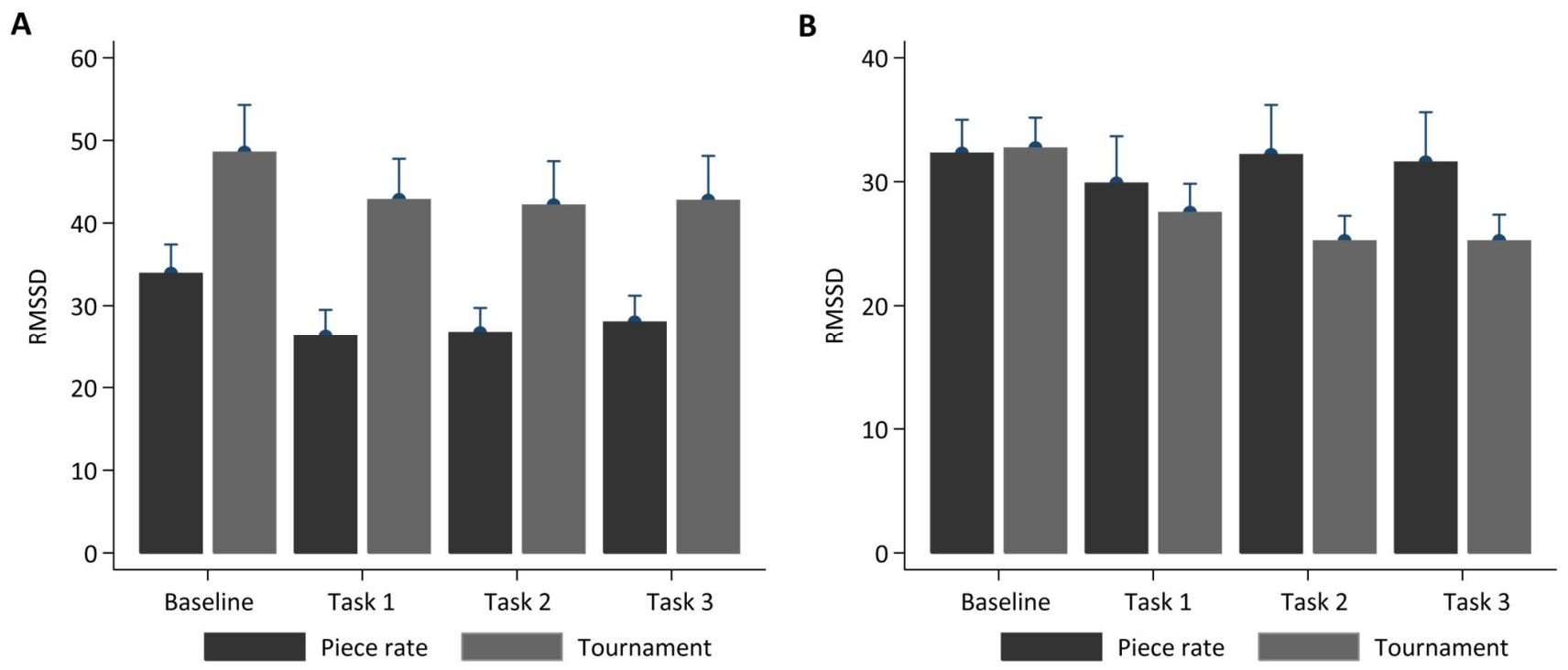

Figure 1: Mean RMSSDs of women (Panel A) and of men (Panel B) by task and choice of payment scheme in Task 3. Error bars indicate the standard error of the mean.

Figure 1A shows that women who choose to enter the tournament in Task 3 have significantly higher baseline heart rate variability than women who choose the piece rate incentives (two-sided t-test for mean RMSSD: $p=0.047$ ). Likewise, we find that the women who choose to enter the tournament in Task 3 have significantly higher heart rate variability during all three tasks (two-sided t-test for mean RMSSD: $p<0.05)$ than women who choose the piece rate incentives. Figure 1B shows that there are no significant differences in baseline or in task-related heart rate variability between the men who choose the tournament and the men who choose the piece rate incentives (two-sided t-test for mean RMSSD: $p$ > 0.10). Taken together, we observe that the women who prefer piece rate payments over tournament 
payments have lower heart rate variability than the women who choose to enter competitive environment, whereas the men who choose to enter competition exhibit similar heart rate variability than the men who choose the piece rate incentives.

Table 3: Probit models on Task-3 payment scheme choice separately for women and men $(1=$ tournament, $0=$ piece rate $)$

\begin{tabular}{lcccc}
\hline & \multicolumn{2}{c}{ Women } & \multicolumn{2}{c}{ Men } \\
& $(1)$ & $(2)$ & $(3)$ & $(4)$ \\
\hline Performance & 0.024 & -0.005 & $0.041^{* * *}$ & 0.014 \\
& $(0.027)$ & $(0.019)$ & $(0.012)$ & $(0.017)$ \\
Baseline RMSSD & $0.009^{* * *}$ & $0.007 * * *$ & -0.002 & -0.001 \\
& $(0.003)$ & $(0.002)$ & $(0.005)$ & $(0.004)$ \\
RMSSD change & -0.006 & $-0.007 * * *$ & $-0.009^{* * *}$ & $-0.006^{* *}$ \\
& $(0.004)$ & $(0.003)$ & $(0.003)$ & $(0.003)$ \\
Confidence & & $-0.124^{*}$ & & $-0.139^{* *}$ \\
& & $(0.065)$ & & $(0.067)$ \\
Risk attitude & & $0.086^{* * *}$ & & -0.018 \\
& & $(0.013)$ & & $(0.024)$ \\
\hline Observations & 38 & 38 & 39 & 39 \\
\hline Pseudo R ${ }^{2}$ & 0.161 & 0.618 & 0.409 & 0.542 \\
Correctly classified $(\%)$ & 63.16 & 86.84 & 79.49 & 89.74 \\
\hline \hline
\end{tabular}

Table reports average marginal effects with standard errors in parentheses. Performance denotes the number of correctly solved arithmetic problems in Task 2. RMSSD change denotes competitioninduced change in heart rate variability measured in normalized RMSSD values. Confidence denotes participants' guesses about their rank among the group members in Task 2 and takes values from 1 to 4, where lower values indicate higher self-confidence. Risk attitude denotes participants' answer to a general risk question on a scale from 1 to 10 where lower values indicate lower willingness to take risks. $* * *$ significant at $\mathrm{p}<0.01, * *$ significant at $\mathrm{p}<0.05, *$ significant at $\mathrm{p}<0.1$.

We find that competition-induced change in heart rate variability is significantly different between the men who enter the tournament in Task 3 and the men who choose the piece rate in Task 3 (two-sided ttest, $p=0.005)$. In particular, we find that heart rate variability decreases between Tasks 1 and 2 among the men who choose the tournament, whereas the heart rate variability increases between Tasks 1 and 2 among the men who choose the piece rate incentives (Fig. S7). By contrast, we do not observe that there are significant differences in competition-induced changes in heart rate variability between those women who enter the tournament in Task 3 and those women who choose the piece rate incentives (two-sided ttest, $\mathrm{p}=0.237)$. 
Table 3 reports probit models separately for women and men to explore the correlates of tournament entry decisions more in detail among men and women. Columns (1) - (2) in Table 3 show that baseline HRV is a statistically significant predictor of tournament entry among women. Column (2) shows that the correlation between baseline HRV and tournament entry among women is robust to controlling for confidence and risk attitudes. By contrast, columns (3) - (4) show that baseline HRV is not a significant predictor of tournament entry among men in any model specification. Despite being statistically significant predictors of tournament entry, it is noteworthy that baseline RMSSD and competitioninduced RMSSD change explain only a modest proportion of variation in participants' tournament entry decisions. ${ }^{20} \mathrm{We}$ summarize these observations as follows:

Result 3: Among women, baseline HRV is positively associated with participants' willingness to participate in a tournament. Among men, the relationship between baseline HRV and competitiveness is not significant.

Result 4: Among men, competition-induced change in HRV is negatively associated with participants' willingness to participate in a tournament. Among women, this effect is significant after controlling for confidence and risk attitudes.

\subsection{Heart rate variability and gender gap in willingness to compete}

A substantial literature has documented a gender gap in competitiveness using the same basic experimental design. We find a significant gender gap in tournament entry in our data after controlling for performance (or probability of winning the tournament). We use regression models reported in Table 2 to assess whether baseline HRV and competition-induced HRV change can account for this gender difference in competitiveness. We are primarily interested to observe how the coefficient of gender dummy changes when we include baseline HRV and competition-induced HRV change in the regressions.

Table 2 shows that the gender difference in tournament entry is 20.2 percentage points after controlling for participants' performance in Task 2. Including the baseline HRV in the regression model increases

\footnotetext{
${ }^{20}$ When running a parsimonious (probit) model for women including only performance as a predictor of tournament entry, the pseudo- $\mathrm{R}^{2}$ is .012 . Adding baseline RMSSD to this parsimonious model increases pseudo- $\mathrm{R}^{2}$ by .005 , while adding risk attitude and self-rated confidence increases it by .386 and .067 , respectively. When running a parsimonious model for men including only performance as a predictor of tournament entry, the pseudo- $\mathrm{R}^{2}$ is .261 . Adding RMSSD change to this parsimonious model increases it by .161 , while adding risk attitude and self-rated confidence increases it by .003 and .173 , respectively.
} 
the gender gap in tournament entry from 20.2 percentage points to 23.8 percentage points (column 2). The increase in the gender gap results from the fact that many relatively high performing women with low baseline HRV choose piece rate incentives. By contrast, including competition-induced HRV change in the regression models decreases the gender difference in tournament entry from 20.2 percentage points to 17.8 percentage points (column 3). Including both HRV variables in the model at the same time (column 4) increases the gender gap again to 24.1 percentage points for the same reason as in model 2. These changes in the gender gap are statistically insignificant (Wald tests for the equality of coefficients: $\mathrm{p}>0.171)$.

The gender gap in competitiveness increases with performance (Fig S4). Table 4 quantifies this observation and shows that the gender gap in tournament entry is 24.5 percentage points among the top performers (performance in Task $2 \geq$ median) after controlling for performance. ${ }^{21}$ The gender gap is approximately 5 percentage points larger among the top performers than in the entire population. The gender gap among the best performers is, however, not significantly larger than in the full sample (Wald tests for the equality of coefficients: $\mathrm{p}=0.560$ ). The observation that high-ability women appear to shy away from competition relative to their ability and expected outcomes is of substantial concern from an efficiency perspective and underlines the importance to study the robustness of our results among the high-performing individuals.

Regression models reported in Table 4 can be used to assess the robustness of the results reported in Table 2 and investigate whether baseline HRV and HRV change can account for gender differences in competitiveness among the best performing individuals. We are again interested to observe how the coefficient of gender dummy changes when we include baseline HRV and HRV change in the regressions. Column (5) in Table 4 shows that the HRV variables are the only significant predictors besides gender in a model which includes also performance, confidence, risk and competition attitudes and competition-induced changes in performance. A comparison of the gender dummy coefficients across different models shows that the inclusion of baseline HRV and HRV change in the regressions has only a minor effect on the gender dummy coefficients. All changes in the gender dummy coefficient across the models reported in Table 4 are statistically insignificant (Wald tests for the equality of coefficients: $p>0.290$ ). We summarize these observations as follows:

\footnotetext{
21 The models reported herein include only participates whose performance in Task 2 is equal to or above the median. We estimate the same model specifications reported in Table 4 also for low performers (below median performance). Among the low performers, the tournament entry decision is mainly associated with performance, confidence and risk attitudes, not by gender or the HRV variables (Table S7).
} 
Result 5: Individual differences in heart rate variability do not eliminate the gender gap in competitiveness.

Table 4: Probit models on Task-3 payment scheme choice for high performers $(1=$ tournament, $0=$ piece rate $)$

\begin{tabular}{|c|c|c|c|c|c|}
\hline & (1) & (2) & (3) & (4) & (5) \\
\hline Woman & $\begin{array}{c}-0.245 * * \\
(0.123)\end{array}$ & $\begin{array}{c}-0.216^{*} \\
(0.112)\end{array}$ & $\begin{array}{c}-0.253^{* *} \\
(0.117)\end{array}$ & $\begin{array}{c}-0.255^{* *} \\
(0.105)\end{array}$ & $\begin{array}{c}-0.221 * * \\
(0.098)\end{array}$ \\
\hline Performance & $\begin{array}{c}0.022 \\
(0.029)\end{array}$ & $\begin{array}{c}0.029 \\
(0.027)\end{array}$ & $\begin{array}{c}0.003 \\
(0.028)\end{array}$ & $\begin{array}{c}0.009 \\
(0.026)\end{array}$ & $\begin{array}{l}-0.002 \\
(0.022)\end{array}$ \\
\hline Baseline RMSSD & & $\begin{array}{c}0.007 * * \\
(0.003)\end{array}$ & & $\begin{array}{c}0.009 * * \\
(0.005)\end{array}$ & $\begin{array}{c}0.007 * * \\
(0.003)\end{array}$ \\
\hline RMSSD change & & & $\begin{array}{l}-0.006 * \\
(0.003)\end{array}$ & $\begin{array}{c}-0.007 * * \\
(0.003)\end{array}$ & $\begin{array}{c}-0.008 * * * \\
(0.002)\end{array}$ \\
\hline Confidence & & & & & $\begin{array}{c}-0.106 \\
(0.064)\end{array}$ \\
\hline Risk attitude & & & & & $\begin{array}{c}0.026 \\
(0.020)\end{array}$ \\
\hline Competition attitude & & & & & $\begin{array}{c}0.023 \\
(0.016)\end{array}$ \\
\hline Performance change & & & & & $\begin{array}{l}-0.321 \\
(0.222)\end{array}$ \\
\hline Observations & 44 & 42 & 42 & 42 & 42 \\
\hline Pseudo $\mathrm{R}^{2}$ & 0.106 & 0.189 & 0.174 & 0.303 & 0.521 \\
\hline Correctly classified $(\%)$ & 75.00 & 80.95 & 76.19 & 83.33 & 90.48 \\
\hline
\end{tabular}

Table presents average marginal effects with standard errors in parentheses. Woman is a dummy variable, where women $=1$ and men $=0$. Performance denotes the number of correctly solved arithmetic problems in Task 2 . RMSSD change denotes competition-induced change in heart rate variability measured in normalized RMSSD values. Confidence denotes participants' guesses about their rank among the group members in Task 2 and takes values from 1 to 4 , where lower values indicate higher self-confidence. Risk attitude denotes participants' answer to a general risk question on a scale from 1 to 10 where lower values indicate lower willingness to take risks. Competition attitude denotes participants' answer to a general competition attitude question on a scale from 1 to 10 where lower values indicate lower willingness to compete. Performance change denotes the difference in the number of correctly solved arithmetic problems between Tasks 2 and 1. Positive values indicate greater performance in the tournament compensation scheme than in the piece rate. $* * *$ significant at $\mathrm{p}<0.01, * *$ significant at $\mathrm{p}<0.05, *$ significant at $\mathrm{p}<0.1$.

\subsection{Potential behavioral pathways}

Our results show that baseline HRV (among women) and competition-induced changes in HRV (among men) are associated with participants' willingness to compete. In this section, we cast a closer look at the regression models reported in Tables $2-4$ and perform additional analyses to investigate potential behavioral mechanisms, which could explain why HRV predicts participants' decisions to compete. 
First, it can be conjectured that there is a direct (causal) relationship between stress (HRV) and competitive preferences. This conjecture implies that stress exposure directly affects preferences for competitiveness. Furthermore, the potential effect of stress on competitive preferences can be divided at least to an effect on preferences for competitive outcomes and to an effect on preferences for performing in competitive environments. Second, as reported, for example, by Van den Bos et al. (2009) and Angelucci and Cordova (2014) certain amounts of (acute) stress can either enhance or reduce productivity and cognitive performance. Third, the relationship between HRV and competitiveness can be explained by participants' changing beliefs about the other participants' performance under competitive incentives. Fourth, the relationship can be mediated by individuals' competitive selfconfidence, risk attitude, ambiguity attitude or any other individual characteristic which shapes individuals' decisions either to compete or withdraw from competition. Finally, given the correlational nature of our data, we naturally cannot exclude the possibility that the relationship is driven by unobservable factors that are related to both HRV and competitiveness.

We examine the potential importance of alternative behavioral mechanisms by controlling for a number of behavioral factors that may be related to competitiveness including participants' performance in the tournament, competitive self-confidence and risk attitude. In addition, our experimental design allows us to examine the relationship between HRV and competitiveness in situations where participants choose their preferred compensation mechanism and knowingly perform under competitive incentives (Task 3 ) and where participants choose their preferred compensation mechanism for past piece rate performance (Task 4).

Notably, we find that baseline HRV and competition-induced changes in HRV are not related to tournament entry in Task 4 (Fig. S4B and Table S6). These observations, together with our Results 1 and 2, suggest that the relationship between HRV and tournament entry is confined to situations where individuals are knowingly performing under competitive incentives. Thus, we do not find support for the conjecture that HRV is related to preferences for competitive outcomes as measured using Task 4 . This observation is congruent with the results reported by Goette et al. (2015) and Cahlikova et al. (2016) who find that exogenously induced acute (social) stress does not affect preferences for competitive outcomes.

By examining the results reported in Tables $2-4$, we observe that performance in the tournament, competitive self-confidence and risk attitude are significantly associated with participants' tournament entry decisions. However, at the same time, we observe that when self-confidence and risk attitude are included as control variables in the regression models, the relationship between tournament entry and 
baseline HRV remains significant. Likewise, the coefficient remains largely unchanged. These findings suggest that the relationship between baseline HRV and competitiveness is unlikely to be driven by changes in self-rated confidence or risk attitude. These observations are also supported by pairwise correlation coefficients reported in Tables S8 - S10 showing that baseline HRV is significantly associated neither with self-rated confidence nor with risk attitude. Likewise, separate analyses reported in Tables S8 - S10 show that participants' performance in tournament is not related to baseline HRV. Taken together, our results allow us exclude the empirical relevance of several proposed mechanisms. We find that the relationship between baseline HRV and competitiveness is unlikely to be driven by stress-induced changes in preferences for competitive outcomes, participants' performance or changing beliefs about the other participants' performance. Likewise, participants' self-rated confidence and riskattitude are unlikely to serve as behavioral mechanisms through which HRV is related to competitiveness in our data. ${ }^{22}$

When examining the results reported in Table 2, we observe that the association between performance and tournament entry decreases after controlling for competition-induced HRV change (RMSSD change) and is not significant after controlling for self-rated confidence, risk attitude, competition attitude and change in performance. We also observe a significant correlation between RMSSD change and performance (Table S8). ${ }^{23}$ In the following, we complement these observations by more closely examining self-rated confidence and RMSSD change as predictors of tournament entry. We perform a mediation analysis following the approach originally developed by Baron and Kenny (1986). Mediation analysis is tested using the bootstrapping method with bias-corrected confidence estimates (MacKinnon et al., 2004; Preacher and Hayes, 2004). The 95\% confidence interval of the indirect effect is obtained with 5000 bootstrap resamples (Preacher \& Hayes, 2008).

We conduct multiple regression analyses to assess each component of the proposed mediation (Fig. 2). First, we find that performance is positively associated with willingness to compete (c-path, beta $=0.232$,

\footnotetext{
${ }^{22}$ One viable alternative for the direct effect on competitive preferences is offered by existing results showing that (acute) stress increases ambiguity aversion among women, while it increases willingness to take unknown risks among men (Van den Bos et al., 2009 and Lighthall et al., 2011). The tournament entry decision in our experiment is related to ambiguous decision making as our participants are not aware of the performance of other participants before their own decisions. Likewise, our approach of evaluating the importance of potential behavioral mechanisms does not help us to gauge the role of any unobservable behavioral factor.

${ }^{23}$ Goette et al. (2015) find that acute stress increases competitive confidence among individuals with low trait anxiety scores, whereas acute stress decreases confidence among highly anxious individuals. We do not find significant associations between HRV change and confidence in the full sample or in any subsample including participants with high or low baseline HRV. In comparison to our paper, Goette et al. (2015) elicit participants' confidence after performing in a test measuring cognitive ability.
} 
$\mathrm{z}=2.792, \mathrm{p}<0.01)$. We also find that performance is negatively associated with self-rated confidence ( $\mathrm{a}_{1}$-path, beta $\left.=-0.130, \mathrm{t}=-5.302, \mathrm{p}<0.001\right)$, and the mediator, confidence, is negatively associated with willingness to compete ( $\mathrm{b}_{1}$-path, beta $=-1.372, \mathrm{z}=-3.155, \mathrm{p}<0.01$ ). However, note that we measure participant's confidence by their beliefs about their relative performance: the lower the participant's guessed rank the higher the participant's self-rated confidence. A negative association between participants' guessed rank and any other variable indicates that the outcome is associated with higher self-rated confidence.

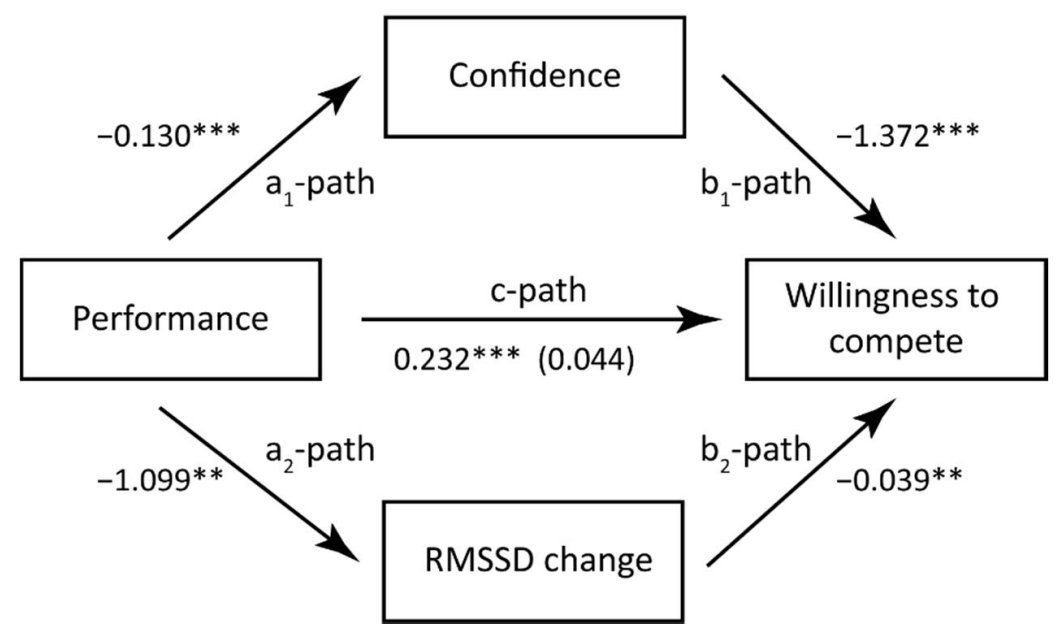

Figure 2: The regression coefficients for the relationship between performance and willingness to compete as mediated by confidence and RMSSD change. The regression coefficient between performance and willingness to compete, controlling for confidence and RMSSD change, is in parentheses. $* * * \mathrm{p}<0.01, * * \mathrm{p}<0.05$.

The results of the mediation analysis confirm the mediating role of the self-rated confidence in the relationship between performance and willingness to compete (indirect effect $=0.179, \mathrm{CI}=[0.078$ 0.308]). In addition, we find that performance is negatively associated with RMSSD change (a $a_{2}$-path, beta $=-1.099, \mathrm{t}=-2.076, \mathrm{p}<0.05)$, and the other mediator, RMSSD change, is negatively associated with willingness to compete ( $\mathrm{b}_{2}$-path, beta $\left.=-0.039, \mathrm{z}=-2.038, \mathrm{p}<0.05\right)$. Thus, the RMSSD change has a mediating role in the relationship between performance and willingness to compete (indirect effect $=0.043,[C I=0.001-0.144])$. Finally, the results indicate that the direct effect of performance on willingness to compete becomes non-significant (beta $=0.044, \mathrm{z}=0.430, \mathrm{p}=0.67$ ) when controlling for 
confidence and RMSSD change, suggesting full mediation. ${ }^{24} \mathrm{We}$ summarize these observations as follows:

Result 6: The relationship between performance and willingness to compete is mediated by competitioninduced HRV change and self-rated confidence.

\section{Conclusions}

This paper aims to increase our understanding of individual differences in competitiveness. We develop an experiment to measure participants' heart rate variability (HRV) in a resting state as well as under non-competitive and competitive incentive schemes. We use these data to examine whether common physiological measures previously related to chronic and acute stress predict participants' willingness to participate in a tournament.

Our study documents an association between HRV and willingness to compete. First, our results show that both baseline HRV and competition-induced changes in HRV predict participants' willingness to participate in a tournament. Second, we find that baseline heart rate variability is associated with competitiveness for women, but not for men. Our results indicate that women with low baseline HRV are more likely to choose piece rate incentives over competitive incentives than women with high baseline HRV. Third, we find that men who experience large decrease in HRV when moving from piece rate to tournament incentives are more likely to choose tournament incentives over piece rate incentives than men with small change in HRV. Fourth, and perhaps most importantly, we observe that HRV does not close the gender gap in competitiveness at the aggregate level. Consequently, our results, speculatively, suggest that policies succeeding to reduce women's exposure to chronic stress at work and home may encourage some women to apply for competitive positions, but does not close the gender gap in competitiveness at the aggregate level among healthy young adults.

Our study investigates the relationship between HRV and competitiveness in a laboratory environment. Our paper has several limitations, including at least (1) the correlational nature of our results, (2) a relatively small sample size, and (3) uncertainty related to the external validity of our results. However, our experiment may pave the way for studies investigating related questions in the field. In particular,

\footnotetext{
${ }^{24}$ The confidence has a mediating role among men (indirect effect $=0.279: \mathrm{CI}=[0.010-2.315]$ ), but not among women. Among women, the association between performance and willingness to compete, the c-path, is also positive, but statistically not significant.
} 
our decision to use unobtrusive and wearable measurement sensors in our physiological measurements may help assessing the external validity of our results.

Only future research can show whether our results are robust to the alternative techniques of stress measurement and replicable in naturally-occurring situations. It also remains to be studied how currently recommended practices for stress management and investments in non-cognitive skills (e.g. sociability, tenacity and self-control) that may help to cope with stress affect individuals' willingness to enter competitive environments.

Acknowledgements: The authors would like to thank Jonas Fooken and Ernesto Reuben for their detailed comments and suggestions when preparing and revising the manuscript. The authors would like to thank Krisztina Timko for research assistance. The paper has benefited from comments made by the participants of the Economic Science Association European Meeting in 2014, the IMEBESS in 2015 and the Annual Congress of the European Economic Association in 2015. This study has been funded by the aivoAALTO project of the Aalto University, the Yrjö Jahnsson Foundation, and the Research Foundation of Cooperative Banks, Finland. The authors declare no conflict of interest.

\section{References}

Acharya, U. R., Joseph, K. P., Kannathal, N., Lim, C. M., \& Suri, J. S. (2006). Heart rate variability: a review. Medical and Biological Engineering and Computing, 44(12), 1031-1051.

Almås, I., Cappelen, A. W., Salvanes, K. G., Sorensen, E., \& Tungodden, B. (2014). Willingness to compete: family matters. NHH Dept. of Economics Discussion Paper, (03).

American Psychological Association (2007). Stress in America Report. Washington, DC: American Psychological Association.

American Psychological Association (2009). Stress in America Report. Washington, DC: American Psychological Association.

Andersen, S., Ertac, S., Gneezy, U., List, J. A., \& Maximiano, S. (2013). Gender, competitiveness, and socialization at a young age: Evidence from a matrilineal and a patriarchal society. Review of Economics and Statistics, 95(4), 1438-1443.

Angelucci, M. \& Cordova, K. (2014). Productivity and Choice under Stress: Are Men and Women Different? Available at: http://www-personal.umich.edu/ mangeluc/ChoiceUnderStress.pdf

Appelhans, B. M., \& Luecken, L. J. (2006). Heart rate variability as an index of regulated emotional responding. Review of general psychology, 10(3), 229-240.

Baron, R.M., \& Kenny, D.A. (1986). The Moderator-mediator Variable Distinction in Socialpsychological Research: Conceptual, Strategic, and Statistical Considerations. Journal of Personality and Social Psychology, 51, 1173-1182. 
Blascovich, J., et al., (2004). Predicting athletic performance from cardiovascular indexes of challenge and threat. Journal of Experimental Social Psychology, 40(5): 683-688.

Blásquez, J. C. C., Font, G. R., \& Ortís, L. C. (2009). Heart-rate variability and precompetitive anxiety in swimmers. Psicothema, 21(4), 531-536.

Brandts, J., \& Garofalo, O. (2012). Gender pairings and accountability effects. Journal of Economic Behavior \& Organization, 83(1), 31-41.

Buckert, M., Schwieren, C., Kudielka, B. M., \& Fiebach, C. J. (2015). How stressful are economic competitions in the lab? An investigation with physiological measures. University of Heidelberg, Discussion Paper Series, No. 593

Buser, T., Dreber, A., \& Mollerstrom, J. (2016). The impact of stress on tournament entry. Experimental Economics, 1-25.

Buser, T., Geijtenbeek, L., \& Plug, E. (2015). Do Gays Shy Away from Competition? Do Lesbians Compete Too Much? IZA Discussion Paper No. 9382, September 2015

Buser, T., Niederle, M. \& Oosterbeek, H. (2014). Gender, competitiveness and career choices. The Quarterly Journal of Economics, 129(3), 1409-1447. doi:10.1093/qje/qju009

Cacioppo, J. T., \& Tassinary, L. G. (1990). Inferring psychological significance from physiological signals. American Psychologist, 45(1), 16.

Cahlikova, J., Cingl, L. \& Levely, I. (2016). How stress affects performance and competitiveness across gender. Mimeo, 2016.

Cárdenas, J. C., Dreber, A., Von Essen, E., \& Ranehill, E. (2012). Gender differences in competitiveness and risk taking: Comparing children in Colombia and Sweden. Journal of Economic Behavior \& Organization, 83(1), 11-23.

Castaldo, R., Melillo, P., Bracale, U., Caserta, M., Triassi, M., \& Pecchia, L. (2015). Acute mental stress assessment via short term HRV analysis in healthy adults: A systematic review with metaanalysis. Biomedical Signal Processing and Control, 18, 370-377.

Ceccato, S., Kudielka, B. M., \& Schwieren, C. (2015). Increased Risk Taking in Relation to Chronic Stress in Adults. Frontiers in Psychology, 6, 2036. http://doi.org/10.3389/fpsyg.2015.02036.

Dekker, J. M., Crow, R. S., Folsom, A. R., Hannan, P. J., Liao, D., Swenne, C. A., \& Schouten, E. G. (2000). Low heart rate variability in a 2-minute rhythm strip predicts risk of coronary heart disease and mortality from several causes. The ARIC Study. Circulation, 102 (11), 1239-1244.

Dohmen, T., Falk, A., Huffman, D., Sunde, U., Schupp, J. \& Wagner, G. G. (2011). Individual risk attitudes: Measurement, determinants, and behavioral consequences. Journal of the European Economic Association, 9(3), 522-550.

Dreber, A., von Essen, E., \& Ranehill, E. (2011). Outrunning the gender gap-boys and girls compete equally. Experimental Economics, 14(4), 567-582.

Dreber, A., von Essen, E., \& Ranehill, E. (2014). Gender and competition in adolescence: task matters. Experimental Economics, 17(1), 154-172.

Dulleck, U., Fooken, J., Newton, C., Ristl, A., Schaffner, M. \& Torgler, B. (2012). Tax compliance and psychic costs: Behavioral experimental evidence using a physiological marker. QuBE Working Papers, QUT Business School 001, QUT Business School. 
Dulleck, U., Schaffner, M. \& Torgler, B. (2014). Heartbeat and economic decisions: Observing mental stress among proposers and responders in the Ultimatum bargaining game. PLoS ONE 09/2014; 9(9):e108218.

Falk, A., Menrath, I., Verde, P.E. \& Siegrist, J. (2011). Cardiovascular consequences of unfair pay. SOEP papers on Multidisciplinary Panel Data Research 380.

Glätzle-Rützler, D. \& Sutter, M. (2014). Gender differences in the willingness to compete emerge early in life and persist. Management Science, 61(10), 2339-23354.

Gneezy, U., Leonard, K. \& List, J. (2009). Gender differences in competition: Evidence from a matrilinear and a patriarchal society. Econometrica, 77, 1637-1664.

Gneezy, U. \& Rustichini, A. (2004). Gender and competition at a young age. American Economic Review, 94 (2), 377-381.

Goette, L., Bendahan, S., Thoresen, J., Hollis, F., \& Sandi, C. (2015). Stress pulls us apart: Anxiety leads to differences in competitive confidence under stress. Psychoneuroendocrinology, 54, 115-123.

Günther, C., Ekinci, N. A., Schwieren, C., \& Strobel, M. (2010). Women can't jump? - An experiment on competitive attitudes and stereotype threat. Journal of Economic Behavior \& Organization, 75(3), $395-401$.

Holt, C.A. \& Laury, S.K. (2002). Risk aversion and incentive effects. The American Economic Review, 92(5), 1644-1655.

Holt-Lunstad, J., Clayton, C. J., \& Uchino, B. N. (2001). Gender differences in cardiovascular reactivity to competitive stress: The impact of gender of competitor and competition outcome. International Journal of Behavioral Medicine, 8(2), 91-102.

Hynynen, E., Konttinen, N., Kinnunen, U., Kyröläinen, H. \& Rusko, H. (2011). The incidence of stress symptoms and heart rate variability during sleep and orthostatic test. European Journal of Applied Physiology, 111 (5), 733-741.

Kandasamy, N., Hardy, B., Page, L., Schaffner, M., Graggaber, J., Powlson, A. S., ... \& Coates, J. (2014). Cortisol shifts financial risk preferences. Proceedings of the National Academy of Sciences, 111(9), 3608-3613.

Lighthall, N. R., Sakaki, M., Vasunilashorn, S., Nga, L., Somayajula, S., Chen, E.Y. \& Mather, M. (2011). Gender differences in reward-related decision processing under stress. Social Cognitive and Affective Neuroscience, 7(4), 476-484.

Lo, A.W. \& Repin, D. V. (2002). The psychophysiology of real-time financial risk processing. Journal of Cognitive Neuroscience, 14(3), 323-339.

MacKinnon, D.P., Lockwood, C.M., \& Williams, J. (2004). Confidence Limits for the Indirect Effect: Distribution of the Product and Resampling Methods. Multivariate Behavioral Research, 39(1), 99. http://doi.org/10.1207/s15327906mbr3901_4

McEwen, B. S. (2007). Physiology and neurobiology of stress and adaptation: central role of the brain. Physiological reviews, 87(3), 873-904.

McEwen, B. S. (2012). Brain on stress: how the social environment gets under the skin. Proceedings of the National Academy of Sciences, 109 (Supplement 2), 17180-17185

Mulder, L. J. M. (1992). Measurement and analysis methods of heart rate and respiration for use in applied environments. Biological psychology, 34(2), 205-236. 
Müller, J. \& Schwieren, C. (2012). Can personality explain what is underlying women's unwillingness to compete? Journal of Economic Psychology, 33(3), 448-460.

Nelson, R. J. (2005). An introduction to behavioral endocrinology. Sinauer Associates.

Niederle M. \& Vesterlund L. (2007). Do women shy away from competition? Do men compete too much? The Quarterly Journal of Economics, 122 (3), 1067-1101.

Niederle, M., \& Vesterlund, L. (2011). Gender and competition. Annual Review of Economics, 3(1), 601-630.

Niederle, M., Segal, C., \& Vesterlund, L. (2013). How costly is diversity? Affirmative action in light of gender differences in competitiveness. Management Science, 59(1), 1-16.

Niizeki, K. \& Saitoh, T. (2012). Incoherent oscillations of respiratory sinus arrhythmia during acute mental stress in humans. Am J Physiol Heart Circ Physiol, 302, 359-367.

Preacher, K.J. \& Hayes, A.F. (2008). Asymptotic and Resampling Strategies for Assessing and Comparing Indirect Effects in Multiple Mediator Models. Behavior Research Methods, 40 (3), 879-891.

Porcelli, A. J. \& Delgado, M. R. (2009). Acute stress modulates risk taking in financial decision making. Psychological Science, 20(3), 278-83.

Reuben, E., Sapienza, P., \& Zingales, L. (2015). Taste for competition and the gender gap among young business professionals. National Bureau of Economic Research, (No. w21695).

Rich, E. L., \& Romero, L. M. (2005). Exposure to chronic stress downregulates corticosterone responses to acute stressors. American Journal of Physiology-Regulatory, Integrative and Comparative Physiology, 288(6), R1628-R1636.

Rivers, J. J., \& Josephs, R. A. (2010). Dominance and health. The social psychology of power, 87-112.

Sapolsky, R. M. (2005). The influence of social hierarchy on primate health. Science, 308(5722), $648-652$.

Tarvainen, M.P., Niskanen, J.-P., Lipponen, J.A., Ranta-aho, P.O. \& Karjalainen, P.A. (2014). Kubios HRV - Heart rate variability analysis software. Computer Methods and Programs in Biomedicine, 113 (1), 210-220.

Task Force of the European Society of Cardiology and the North American Society of Pacing and Electrophysiology, (1996). Heart rate variability: standards of measurement, physiological interpretation and clinical use. Circulation 93(5), 1043-1065.

Tytherleigh, M. Y., Jacobs, P. A., Webb, C., Ricketts, C., \& Cooper, C. (2007). Gender, Health and Stress in English University Staff_Exposure or Vulnerability? Applied Psychology, 56(2), 267-287.

Van den Bos, R., Harteveld, M., \& Stoop, H. (2009). Stress and decision-making in humans: performance is related to cortisol reactivity, albeit differently in men and women. Psychoneuroendocrinology, 34(10), 1449-1458.

Zulfiqar, U., Jurivich, D. A., Gao, W., \& Singer, D. H. (2010). Relation of high heart rate variability to healthy longevity. The American Journal of Cardiology, 105(8), 1181-1185.

Zhang, Y. J. (2014). Culture and the gender gap in competitive inclination: evidence from the communist experiment in China. Available at SSRN 2268874. 


\title{
Electronic Supplementary Material for Competitive Behavior, Stress, and Gender
}

\author{
Marja-Liisa Halko ${ }^{\mathrm{a}, \mathrm{b}}$, Lauri Sääksvuori ${ }^{\mathrm{c}, \mathrm{d}}$ \\ ${ }^{a}$ Department of Political and Economic Studies, P.O. Box 17, \\ 00014 University of Helsinki, Finland
}

${ }^{\mathrm{b}}$ Department of Economics, School of Business, P.O. Box 21240, 00076 Aalto University, Finland

${ }^{c}$ National Institute for Health and Welfare, Centre for Health and Social Economics, P.O.Box

30, 00271 Helsinki, Finland

${ }^{\mathrm{d}}$ Joint Research Centre, European Commission, Italy

Address correspondence to:

marja-liisa.halko@helsinki.fi

1. Material and methods.......................................... p.1

2. Supplementary results, figures and tables.......................p.3

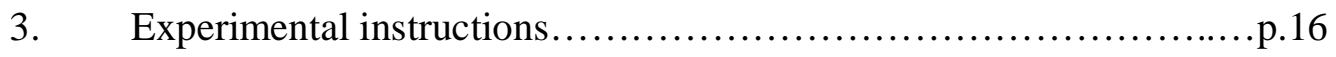




\section{Material and methods}

The experiment was conducted using the z-Tree software (Fischbacher, 2007) in the PCRC Decision Making Laboratory at the University of Turku, Finland. We used a standard subject pool which mainly consists of university students enrolled at the University of Turku. The experiment was conducted in two consecutive days. There were two consecutive sessions per day. There were 20 participants in each session. The total number of participants was 80, consisting of 39 male and 41 female participants. Invitation letters to the subject pool members stated that participants' heart rate variability will be measured during the experiment. Only non-smoking participants were allowed to participate in the experiment. The experimental protocol was approved in advance by the Research Ethics Committee of the Aalto University, Finland. All subjects signed informed consent forms before participating in the experiment.

\subsection{Tasks and timing}

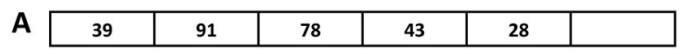

\begin{tabular}{|c|c|c|c|}
\hline & Task / feedback & Payment scheme & $\begin{array}{c}\text { Duration } \\
\text { (min.) }\end{array}$ \\
\hline Preparatorytasks & $\begin{array}{l}\text { Filling questionnaires, } \\
\text { practice }\end{array}$ & - & $\sim 10$ \\
\hline Task 1 & $\begin{array}{l}\text { Adding numbers, } \\
\text { individual }\end{array}$ & Piece rate & 5 \\
\hline Pause & $\begin{array}{l}\text { No. of problems solved / } \\
\text { correctly solved in Task } 1\end{array}$ & - & 5 \\
\hline Task 2 & $\begin{array}{l}\text { Adding numbers, } \\
\text { groups }\end{array}$ & Tournament & 5 \\
\hline Pause & $\begin{array}{l}\text { No. of problems solved / } \\
\text { correctly solved in Task } 2\end{array}$ & - & 5 \\
\hline Task 3 & $\begin{array}{l}\text { Adding numbers, } \\
\text { individual or groups }\end{array}$ & $\begin{array}{l}\text { Piece rate or } \\
\text { tournament }\end{array}$ & 5 \\
\hline Pause & $\begin{array}{l}\text { No. of problems solved / } \\
\text { correctly solved in Task } 3\end{array}$ & - & 4 \\
\hline Task 4 & $\begin{array}{l}\text { No. of problems solved / cor- } \\
\text { rectly solved in Task } 1 \\
\text { Choice: piece rate or tourna- } \\
\text { ment for Task } 1\end{array}$ & $\begin{array}{l}\text { Piece rate or } \\
\text { tournament }\end{array}$ & $\sim 2$ \\
\hline Pause & $\begin{array}{l}\text { Rank guess in Task } 1 \text {, } \\
\text { rank guess in Task } 2\end{array}$ & $\begin{array}{l}\text { Payments from correct } \\
\text { guesses }\end{array}$ & 4 \\
\hline Task 5 & $\begin{array}{l}\text { Adding numbers, } \\
\text { individual or new groups }\end{array}$ & $\begin{array}{l}\text { Piece rate or } \\
\text { tournament }\end{array}$ & 5 \\
\hline After the tasks & $\begin{array}{l}\text { Rank guess in Task } 5 \text {, } \\
\text { filling questionnaires, }\end{array}$ & $\begin{array}{l}\text { Payment from a correct } \\
\text { guess, Holt \& Laury }\end{array}$ & $\sim 18$ \\
\hline
\end{tabular}

Figure S1: A) An example set of five, randomly drawn, two-digit numbers. The task of the subjects was to fill in the sum of the numbers in the blank box. B) The timing of the tasks of the experiment. As shown in the figure, the experiment included a fifth task. In this task, participants are requested to choose between a piece rate and tournament compensation scheme and perform the five-minute arithmetic task once again. The difference between Task 3 and Task 5 is that in Task 5 only those participants who choose a tournament compensation scheme will be compared with each other. Results from the fifth task are reported elsewhere. 


\subsection{Information about the heart rate variability measurement device}

We measured our participants' beat-to-beat intervals using the FirstBeat Bodyguard1 heart rate monitor. The device was attached to skin using two electrodes: one (yellow snap) to the right side of the body, just below the collar bone, and the another (red snap) to the left side of the body below the heart (on the rib cage). Participants attach the HRV measurement devices to their chest by themselves. Attaching these devices is straightforward and does not require any particular skill. In particular, the device is easy to install under clothes. Attaching the device to a female body does not substantially differ from attaching the device to a male body. The measurement accuracy for recording beat-to-beat intervals is 1 ms with a sampling frequency of $1000 \mathrm{~Hz}$. The accuracy of the measurement device does not differ from standard clinical ECG recording devices with off-line R-wave detection (Parak and Korhonen, 2013).
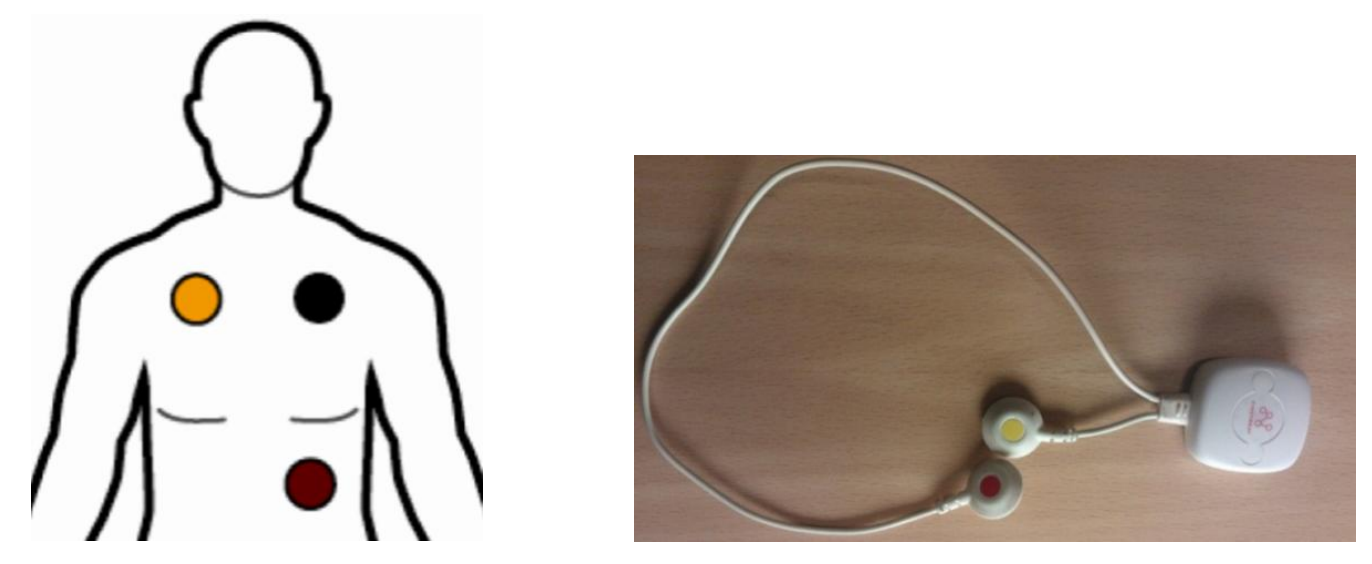

Figure S2. On the left, the device is placed with electrodes, one electrode to the right side of the body, below the collarbone (yellow dot), and one electrode to the left side of the body, to the rib cage (red dot). On the right, the heart rate variability measurement device.

\subsection{Computation of the root mean square of successive intervals}

We use throughout the paper the Root Mean Square of Successive Differences (RMSSD) to measure the variation of beat-to-beat (BTB) intervals. The RMMSD is defined as

$$
R M S S D=\sqrt{\frac{1}{N-1} \sum_{j=1}^{N-1}\left(B T B_{j+1}-B T B_{j}\right)^{2}}
$$

where $B T B_{j}$ denotes the value of $\mathrm{j}$ th beat-to-beat interval and $\mathrm{N}$ is the total number of successive intervals. 


\section{Supplementary results, figures and tables}

\subsection{Winning probability by simulation}

We use simulated winning probabilities to assess the economic magnitude of participants' tournament entry decisions and to evaluate the robustness of the results reported in this paper. We assess the probability of winning the tournament by performing a simulation where we draw 10000 groups consisting of two men and two women using the sample of 39 men and 41 women with replacement. We repeat this 100 times and arrive at a result that, conditional on gender, the probability of winning the Task 2 tournament is 30.1 percent for a man and 19.4 percent for a woman. In a sample of 39 men and 41 women, this difference is marginally significant (two-sided t-test, $\mathrm{p}=0.08$ ). In particular, the probability of winning the tournament begins to diverge for performances greater than 13 correctly solved problems (Fig. S3). The probability of winning the tournament with 13 correctly solved problems is 55.5 percent for a man and 48.8 percent for a woman. The probability of winning the tournament with 15 correctly solved problems is 75.3 percent for a man and 66.2 percent for a woman.

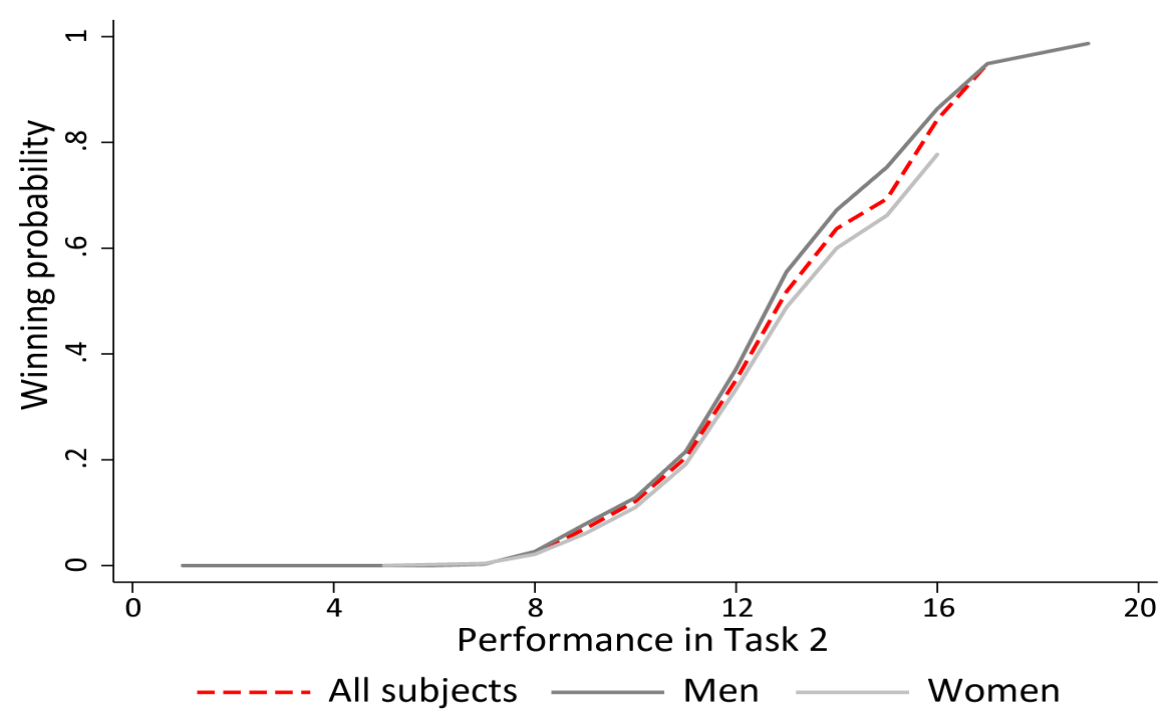

Figure S3: The probability of winning the tournament for a given performance among the men and women. 


\subsection{The economic magnitude of decisions between piece rate and tournament incentives}

Following the analysis reported in Niederle \& Vesterlund (2007), we use simulated winning probabilities to assess the economic magnitude of the decisions between piece rate and tournament incentives in our experiment. We find that participants with 12 or more correct answers in the tournament have a 35 percent or higher chance of winning the tournament. Assuming that individuals with 12 or more correct answers know the performance distribution and maintain exactly the same performance in Task 3 , the decision to enter the tournament for participants with 12 or more correct answers is a gamble of receiving 12 Euros with a 35 percent probability (expected value of 4.2 Euros) versus a sure gain of 3.00 Euros.

Participants with 13 or more correct answers in the tournament have a 53 percent or higher chance of winning the tournament. Assuming that individuals with 13 or more correct answers know the performance distribution and maintain exactly the same performance in Task 3 , the decision to enter the tournament for participants with 13 or more correct answers is a gamble of receiving 13 Euros with a 53 percent probability (expected value of 6.90 Euros) versus a sure gain of 3.25 Euros. Of the participants who solve 13 problems or more, 63 percent of the women (five out of eight) and 100 percent of the men (eleven out of eleven) take this or a better gamble.

Participants with 14 or more correct answers in the tournament have a 64 percent or higher chance of winning the tournament. Assuming that individuals with 14 or more correct answers know the performance distribution and maintain exactly the same performance in Task 3 , the decision to enter the tournament for participants with 14 or more correct answers is a gamble of receiving 14 Euros with a 64 percent probability (expected value of 9.00 Euros) versus a sure gain of 3.50 Euros. Of the participants who solve 14 problems or more, 50 percent of the women (two out of four) and 100 percent of the men (eight out of eight) take this or a better gamble. 


\subsection{Supplementary figures}

A

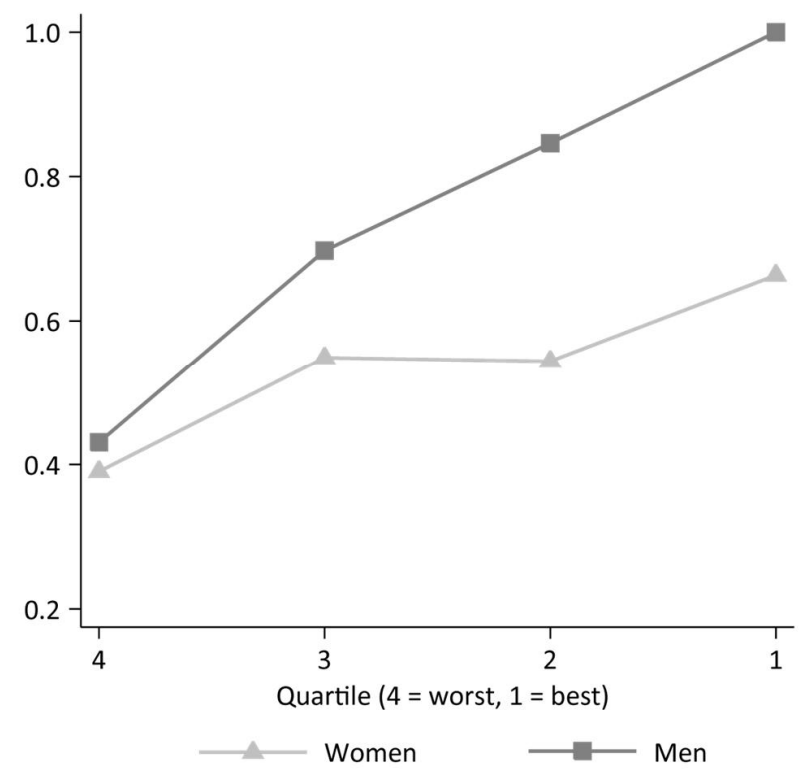

B

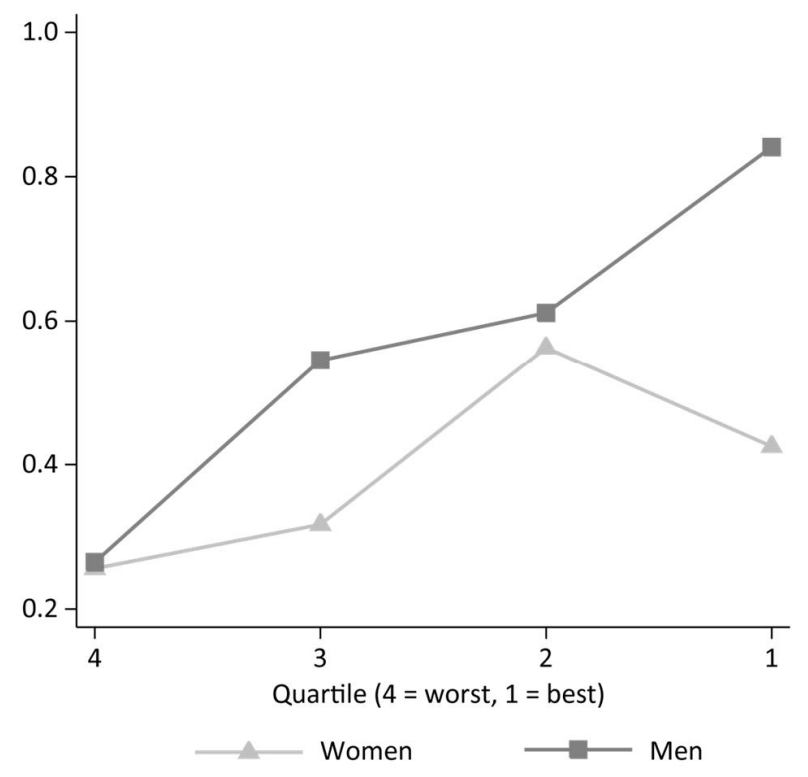

Figure S4: The proportion of participants selecting the tournament in Task 3 conditional on Task 2 tournament performance quartile (Panel A) and the proportion of participants selecting the tournament in Task 4 conditional on Task 1 performance quartile (Panel B).

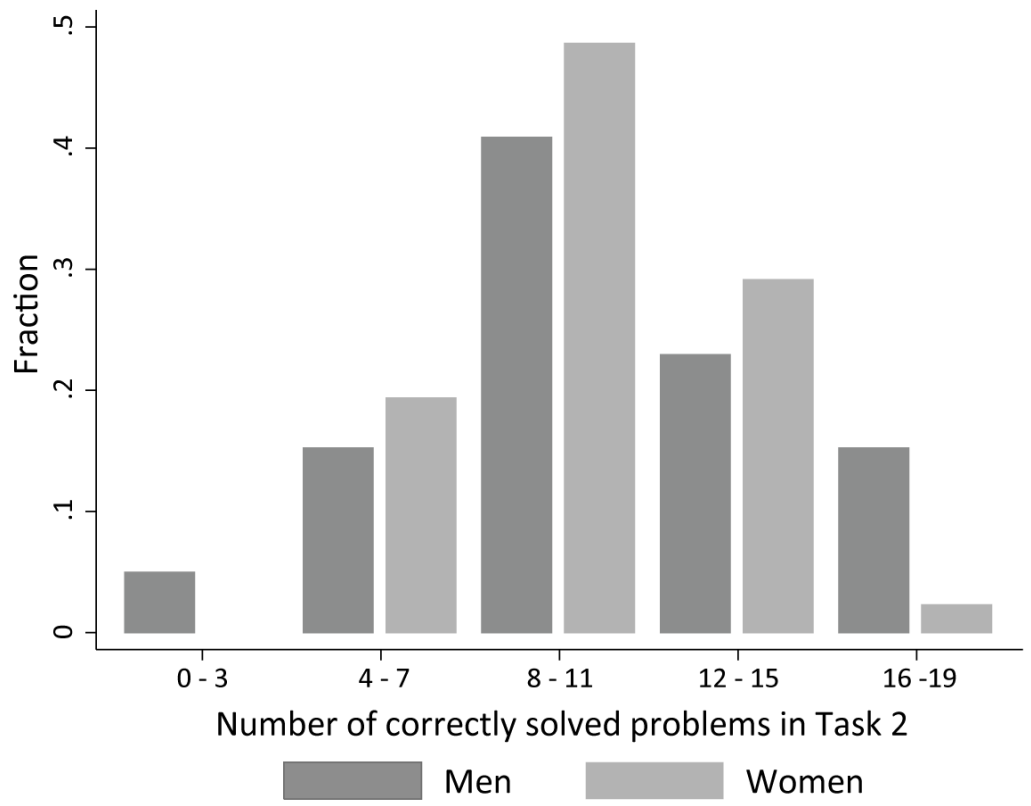

Figure S5: The performance distribution of men and women in Task 2. 
A

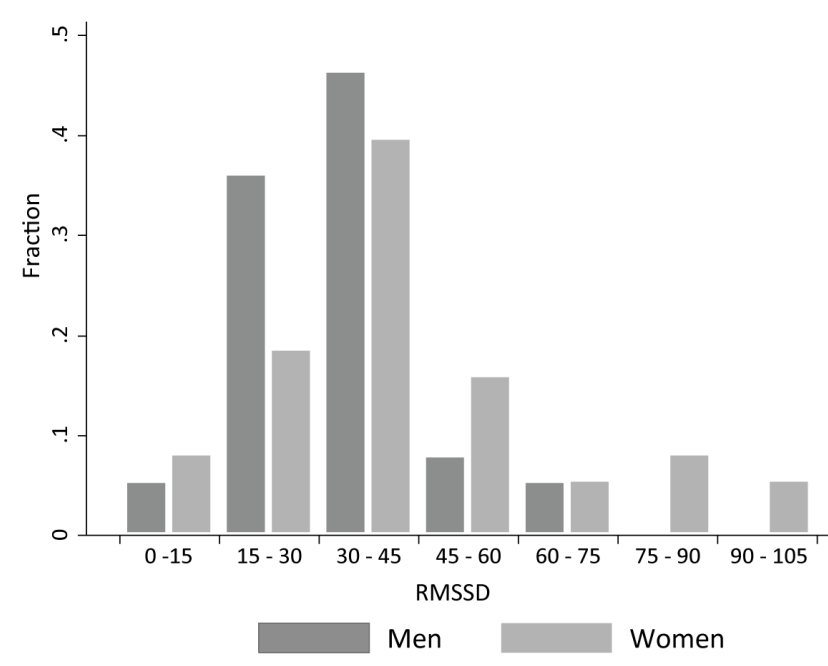

B

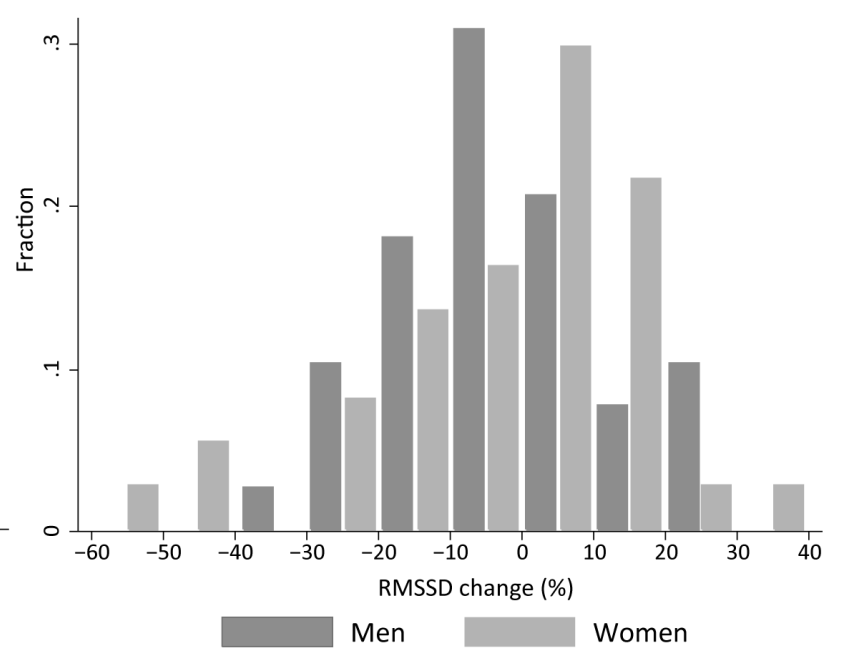

Figure S6: A) The distribution of RMMSD values during the baseline measurement among the men and women. B) The distribution of competition-induced changes in heart rate variability among the men and women.

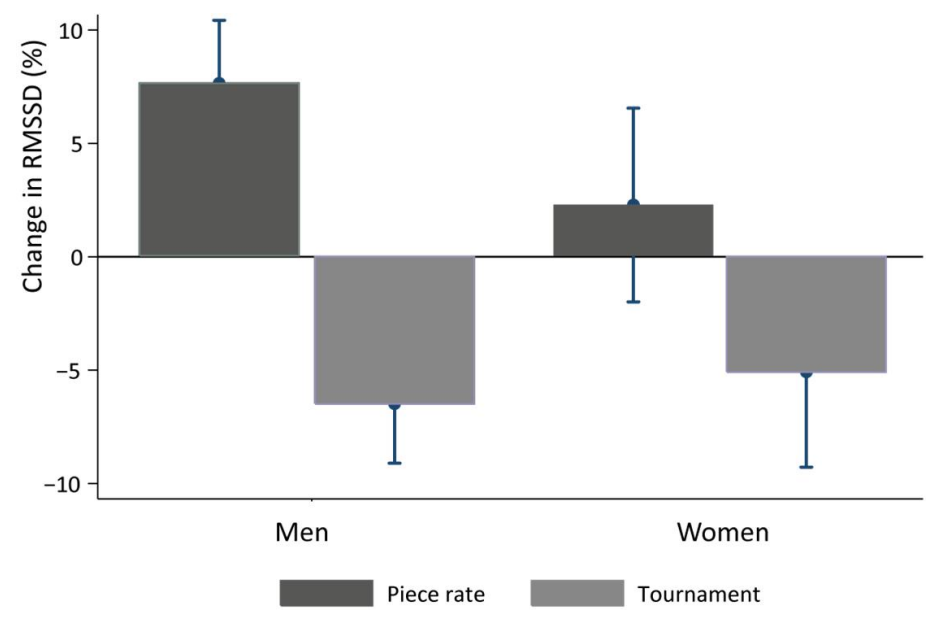

Figure S7: Figure shows competition-induced changes in heart rate variability by gender and choice of payment scheme in Task 3 using the relative RMSSD measure defined in Equation 1, that is, the mean difference between RMSSD (Task2) - RMSSD (Task1), relative to the Task 1 RMMSD, by gender and choice of payment scheme in Task 3. Error bars indicate the standard error of the mean. 


\subsection{Supplementary tables}

Table S1: Probit models on Task-3 payment scheme choice $(1=$ tournament, $0=$ piece rate $)$

\begin{tabular}{|c|c|c|c|c|c|}
\hline & (1) & (2) & (3) & (4) & (5) \\
\hline Woman & $\begin{array}{l}-0.165^{*} \\
(0.095)\end{array}$ & $\begin{array}{c}-0.200^{* * *} \\
(0.093)\end{array}$ & $\begin{array}{l}-0.148 \\
(0.094)\end{array}$ & $\begin{array}{c}-0.207 * * \\
(0.089)\end{array}$ & $\begin{array}{l}-0.130^{*} \\
(0.073)\end{array}$ \\
\hline Probability of winning & $\begin{array}{c}0.564 * * * \\
(0.191)\end{array}$ & $\begin{array}{c}0.575 * * * \\
(0.185)\end{array}$ & $\begin{array}{c}0.419 * * \\
(0.195)\end{array}$ & $\begin{array}{c}0.448^{* *} \\
(0.181)\end{array}$ & $\begin{array}{c}0.127 \\
(0.166)\end{array}$ \\
\hline Baseline RMSSD & & $\begin{array}{c}0.006^{* *} \\
(0.003)\end{array}$ & & $\begin{array}{c}0.007 * * * \\
(0.003)\end{array}$ & $\begin{array}{c}0.007 * * * \\
(0.002)\end{array}$ \\
\hline RMSSD change & & & $\begin{array}{c}-0.006 * * \\
(0.003)\end{array}$ & $\begin{array}{c}-0.007 * * \\
(0.003)\end{array}$ & $\begin{array}{c}-0.007 * * * \\
(0.002)\end{array}$ \\
\hline Confidence & & & & & $\begin{array}{c}-0.199 * * * \\
(0.042)\end{array}$ \\
\hline Risk attitude & & & & & $\begin{array}{c}0.040 * * \\
(0.016)\end{array}$ \\
\hline Competition attitude & & & & & $\begin{array}{c}0.006 \\
(0.013)\end{array}$ \\
\hline Performance change & & & & & $\begin{array}{l}-0.134 \\
(0.090)\end{array}$ \\
\hline Observations & 80 & 77 & 77 & 77 & 77 \\
\hline Pseudo $\mathrm{R}^{2}$ & 0.111 & 0.156 & 0.145 & 0.212 & 0.479 \\
\hline Correctly classified (\%) & 65.00 & 67.53 & 63.64 & 71.43 & 85.71 \\
\hline
\end{tabular}

Table presents average marginal effects with standard errors in parentheses. Woman is a dummy variable, where women $=1$ and men $=0$. Probability of winning denotes participants' simulated probability of winning the tournament in Task 2. RMSSD change denotes competition-induced change in heart rate variability measured in normalized RMSSD values. Confidence denotes participants' guesses about their rank among the group members in Task 2 and takes values from 1 to 4, where lower values indicate higher self-confidence. Risk attitude denotes participants' answer to a general risk question on a scale from 1 to 10 where lower values indicate lower willingness to take risks. Competition attitude denotes participants' answer to a general competition attitude question on a scale from 1 to 10 where lower values indicate lower willingness to compete. Performance change denotes the difference in the number of correctly solved arithmetic problems between Tasks 2 and 1. Positive values indicate greater performance in the tournament compensation scheme than in the piece rate. $* * * s i g n i f i c a n t$ at $\mathrm{p}<0.01, * *$ significant at $\mathrm{p}<0.05, *$ significant at $\mathrm{p}<0.1$. 
Table S2: Probit models on Task-3 payment scheme choice $(1=$ tournament, $0=$ piece rate $)$

\begin{tabular}{|c|c|c|c|c|c|}
\hline & (1) & (2) & (3) & (4) & (5) \\
\hline Woman & $\begin{array}{c}-0.202 * * \\
(0.092)\end{array}$ & $\begin{array}{c}-0.237 * * * \\
(0.090)\end{array}$ & $\begin{array}{l}-0.177^{*} \\
(0.090)\end{array}$ & $\begin{array}{c}-0.242 * * * \\
(0.084)\end{array}$ & $\begin{array}{c}-0.142 * * \\
(0.071)\end{array}$ \\
\hline Performance & $\begin{array}{c}0.048 * * * \\
(0.013)\end{array}$ & $\begin{array}{c}0.049 * * * \\
(0.013)\end{array}$ & $\begin{array}{c}0.038 * * * \\
(0.013)\end{array}$ & $\begin{array}{c}0.040 * * * \\
(0.012)\end{array}$ & $\begin{array}{c}0.014 \\
(0.014)\end{array}$ \\
\hline Baseline RMSSD & & $\begin{array}{c}0.006^{* *} \\
(0.003)\end{array}$ & & $\begin{array}{c}0.007 * * * \\
(0.003)\end{array}$ & $\begin{array}{c}0.007 * * * \\
(0.002)\end{array}$ \\
\hline $\begin{array}{l}\text { RMSSD change } \\
\text { (normalized to the } \\
\text { baseline) }\end{array}$ & & & $\begin{array}{c}-0.006 * * \\
(0.003)\end{array}$ & $\begin{array}{c}-0.007 * * * \\
(0.003)\end{array}$ & $\begin{array}{c}-0.007 * * * \\
(0.002)\end{array}$ \\
\hline Confidence & & & & & $\begin{array}{c}-0.186 * * * \\
(0.042)\end{array}$ \\
\hline Risk attitude & & & & & $\begin{array}{c}0.039 * * \\
(0.016)\end{array}$ \\
\hline Competition attitude & & & & & $\begin{array}{c}0.005 \\
(0.013)\end{array}$ \\
\hline Performance change & & & & & $\begin{array}{c}-0.144 * \\
(0.089)\end{array}$ \\
\hline Observations & 80 & 77 & 77 & 77 & 77 \\
\hline Pseudo $\mathrm{R}^{2}$ & 0.137 & 0.186 & 0.182 & 0.258 & 0.512 \\
\hline Correctly classified (\%) & 66.25 & 76.62 & 68.83 & 67.53 & 87.01 \\
\hline
\end{tabular}

Table reports average marginal effects with standard errors in parentheses. Woman is a dummy variable, where women $=1$ and men $=0$. Performance denotes the number of correctly solved arithmetic problems in Task 2 . RMSSD change denotes competition-induced change in heart rate variability measured in normalized RMSSD values. Confidence denotes participants' guesses about their rank among the group members in Task 2 and takes values from 1 to 4, where lower values indicate higher self-confidence. Risk attitude denotes participants' answer to a general risk question on a scale from 1 to 10 where lower values indicate lower willingness to take risks. Competition attitude denotes participants' answer to a general competition attitude question on a scale from 1 to 10 where lower values indicate lower willingness to compete. Performance change denotes the difference in the number of correctly solved arithmetic problems between Tasks 2 and 1 . Positive values indicate greater performance in the tournament compensation scheme than in the piece rate. $* * *$ significant at $p<0.01$, $* *$ significant at $\mathrm{p}<0.05$, *significant at $\mathrm{p}<0.1$. 
Table S3: Placebo regressions for Task-3 and Task-4 payment scheme choice $(1=$ tournament, $0=$ piece rate $)$

\begin{tabular}{|c|c|c|c|c|c|c|}
\hline & \multicolumn{5}{|c|}{ Task 3} & \multirow{2}{*}{$\begin{array}{c}\text { Task } 4 \\
(6)\end{array}$} \\
\hline & (1) & (2) & (3) & (4) & (5) & \\
\hline & All & Women & Men & Men top 50\% & Men top 50\% & All \\
\hline Woman & $\begin{array}{l}-0.568 \\
(0.323)\end{array}$ & & & & & $\begin{array}{l}-0.327 \\
(0.298)\end{array}$ \\
\hline Performance & $\begin{array}{c}0.182 * * * \\
(0.057)\end{array}$ & $\begin{array}{c}0.104 \\
(0.084)\end{array}$ & $\begin{array}{c}0.238 * * * \\
(0.091)\end{array}$ & & & $\begin{array}{l}0.116 * * \\
(0.050)\end{array}$ \\
\hline Baseline - Task 1 & $\begin{array}{l}-1.331 \\
(0.836)\end{array}$ & $\begin{array}{l}-2.108 * \\
(1.136)\end{array}$ & $\begin{array}{l}-0.514 \\
(1.377)\end{array}$ & $\begin{array}{c}28.725 \\
(28.246)\end{array}$ & $\begin{array}{c}-3.473 \\
(50.471)\end{array}$ & $\begin{array}{l}-0.007 \\
(0.764)\end{array}$ \\
\hline Confidence & & & & $\begin{array}{c}0.503 \\
(1.753)\end{array}$ & & \\
\hline $\begin{array}{l}\text { Confidence } \times \\
\text { Baseline }- \text { Task } 1\end{array}$ & & & & $\begin{array}{l}-13.643 \\
(13.755)\end{array}$ & & \\
\hline Risk attitude & & & & & $\begin{array}{l}-1.148 \\
(0.991)\end{array}$ & \\
\hline $\begin{array}{l}\text { Risk attitude } \times \\
\text { Baseline - Task } 1\end{array}$ & & & & & $\begin{array}{l}1.808 \\
(6.688)\end{array}$ & \\
\hline Constant & $\begin{array}{l}-0.890^{*} \\
(0.532)\end{array}$ & $\begin{array}{l}-0.564 \\
(0.815)\end{array}$ & $\begin{array}{l}-0.564 \\
(0.815)\end{array}$ & $\begin{array}{c}0.221 \\
(3.419)\end{array}$ & $\begin{array}{c}7.609 \\
(6.237)\end{array}$ & $\begin{array}{l}-0.863^{*} \\
(0.481)\end{array}$ \\
\hline Observations & 77 & 38 & 39 & 20 & 20 & 77 \\
\hline Pseudo $\mathrm{R}^{2}$ & 0.156 & 0.082 & 0.264 & 0.396 & 0.355 & 0.078 \\
\hline Correctly classified (\%) & 67.53 & 68.42 & 82.05 & 95.00 & 85.00 & 63.64 \\
\hline
\end{tabular}

Table reports probit regression coefficients with standard errors in parenthesis. Woman is a dummy variable, where women $=1$ and men $=0$. Performance denotes the number of correctly solved arithmetic problems in Task 2 in columns 1-5. Performance denotes the number of correctly solved arithmetic problems in Task 1 in column 6. Baseline - Task 1 denotes the difference in RMSSD between the baseline measurement and Task1 measurement in normalized RMSSD values. Confidence denotes participants' guesses about their rank among the group members in Task 2 and takes values from 1 to 4 , where lower values indicate higher self-confidence. Risk attitude denotes participants' answer to a general risk question on a scale from 1 to 10 where lower values indicate lower willingness to take risks. Confidence $\times$ Baseline - Task 1 and Risk attitude $\times$ Baseline - Task 1 are interaction terms. $* * *$ significant at $\mathrm{p}<0.01, * *$ significant at $\mathrm{p}<0.05$, *significant at $\mathrm{p}<0.1$. 
Table S4: Probit models on Task-3 payment scheme choice $(1=$ tournament, $0=$ piece rate $)$

(1)

(2)

$-0.202 * *$
$(0.092)$

$0.048 * * *$

(0.013)

Baseline RMSSD

(60 min period)

RMSSD change

Confidence

Woman

Performance

Risk attitude

(3)

(4)

$-0.178 *$

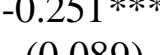

$(0.091)$

$-0.259 * * *$

(0.084)

$0.051 * * *$

$0.038 * * *$

$0.043 * * *$

(0.014)

(0.013)

$0.009 * * *$

(0.003)

$(0.003)$

$-0.007 * * *$

$-0.006 * *$

$(0.003)$

(0.002)

$-0.007 * * *$

(0.002)

$-0.178 * * *$

(0.043)

$0.038 * *$

(0.016)

0.015

(0.013)

Performance change

$-0.162 *$

(0.092)

\begin{tabular}{lccccc}
\hline Observations & 80 & 77 & 77 & 77 & 77 \\
\hline Pseudo $\mathrm{R}^{2}$ & 0.137 & 0.200 & 0.168 & 0.261 & 0.523 \\
Correctly classified (\%) & 66.25 & 72.73 & 67.53 & 71.43 & 85.71 \\
\hline
\end{tabular}

Table reports average marginal effects with standard errors in parentheses. Woman is a dummy variable, where women $=1$ and men $=0$. Performance denotes the number of correctly solved arithmetic problems in Task 2 . RMSSD change denotes competition-induced change in heart rate variability measured in normalized RMSSD values. Confidence denotes participants' guesses about their rank among the group members in Task 2 and takes values from 1 to 4 , where lower values indicate higher self-confidence. Risk attitude denotes participants' answer to a general risk question on a scale from 1 to 10 where lower values indicate lower willingness to take risks. Competition attitude denotes participants' answer to a general competition attitude question on a scale from 1 to 10 where lower values indicate lower willingness to compete. Performance change denotes the difference in the number of correctly solved arithmetic problems between Tasks 2 and 1. Positive values indicate greater performance in the tournament compensation scheme than in the piece rate. $* * *$ significant at $\mathrm{p}<0.01$, ** significant at $\mathrm{p}<0.05$, *significant at $\mathrm{p}<0.1$. 
Table S5: Probit models on Task-3 payment scheme choice $(1=$ tournament, $0=$ piece rate $)$

\begin{tabular}{|c|c|c|c|c|c|}
\hline & (1) & (2) & (3) & (4) & (5) \\
\hline Woman & $\begin{array}{l}-0.202 * * \\
(0.092)\end{array}$ & $\begin{array}{c}-0.237 * * * * \\
(0.090)\end{array}$ & $\begin{array}{l}-0.178^{*} \\
(0.091)\end{array}$ & $\begin{array}{c}-0.241 * * * \\
(0.086)\end{array}$ & $\begin{array}{c}-0.156^{* *} \\
(0.075)\end{array}$ \\
\hline Performance & $\begin{array}{c}0.048 * * * \\
(0.013)\end{array}$ & $\begin{array}{c}0.049 * * * \\
(0.013)\end{array}$ & $\begin{array}{c}0.038 * * * \\
(0.014)\end{array}$ & $\begin{array}{c}0.040 * * * \\
(0.013)\end{array}$ & $\begin{array}{c}0.018 \\
(0.014)\end{array}$ \\
\hline Baseline RMSSD & & $\begin{array}{l}0.006 * * \\
(0.003)\end{array}$ & & $\begin{array}{c}0.007 * * * \\
(0.003)\end{array}$ & $\begin{array}{c}0.008 * * * \\
(0.002)\end{array}$ \\
\hline RMSSD change & & & $\begin{array}{c}-0.006^{* *} \\
(0.003\end{array}$ & $\begin{array}{c}-0.006^{* *} \\
(0.003)\end{array}$ & $\begin{array}{c}-0.006^{* * * *} \\
(0.002)\end{array}$ \\
\hline Confidence & & & & & $\begin{array}{c}-0.204 * * * \\
(0.049)\end{array}$ \\
\hline $\begin{array}{l}\text { Risk attitude } \\
\text { (Holt \& Laury) }\end{array}$ & & & & & $\begin{array}{c}-0.046 * * * \\
(0.016)\end{array}$ \\
\hline Competition attitude & & & & & $\begin{array}{c}0.006 \\
(0.014)\end{array}$ \\
\hline Performance change & & & & & $\begin{array}{c}-0.196^{* *} \\
(0.090)\end{array}$ \\
\hline Observations & 80 & 77 & 77 & 77 & 73 \\
\hline Pseudo $\mathrm{R}^{2}$ & 0.137 & 0.186 & 0.168 & 0.240 & 0.497 \\
\hline Correctly classified (\%) & 66.25 & 76.62 & 67.53 & 71.43 & 83.56 \\
\hline \multicolumn{6}{|c|}{$\begin{array}{l}\text { Table presents average marginal effects with standard errors in parentheses. Woman is a dummy variable, where women }=1 \\
\text { and men }=0 \text {. Performance denotes the number of correctly solved arithmetic problems in Task } 2 \text {. RMSSD change denotes } \\
\text { competition-induced change in heart rate variability measured in normalized RMSSD values. Confidence denotes } \\
\text { participants' guesses about their rank among the group members in Task } 2 \text { and takes values from } 1 \text { to } 4 \text {, where lower values } \\
\text { indicate higher self-confidence. Risk attitude (Holt \& Laury) denotes the point where participants switch from the low risk } \\
\text { option to the high risk option. Higher values indicate lower willingness to take risks. Competition attitude denotes } \\
\text { participants' answer to a general competition attitude question on a scale from } 1 \text { to } 10 \text { where lower values indicate lower } \\
\text { willingness to compete. Performance change denotes the difference in the number of correctly solved arithmetic problems } \\
\text { between Tasks } 2 \text { and } 1 \text {. Positive values indicate greater performance in the tournament compensation scheme than in the } \\
\text { piece rate. } * * * \text { significant at } p<0.01 \text {, **significant at } p<0.05 \text {, *significant at } p<0.1 \text {. }\end{array}$} \\
\hline
\end{tabular}


Table S6: Probit models on Task-4 payment scheme choice $(1=$ tournament, $0=$ piece rate $)$

\begin{tabular}{|c|c|c|c|c|c|}
\hline & (1) & (2) & (3) & (4) & (5) \\
\hline Woman & $\begin{array}{l}-0.121 \\
(0.103)\end{array}$ & $\begin{array}{c}-0.123 \\
(0.108)\end{array}$ & $\begin{array}{c}-0.119 \\
(0.105)\end{array}$ & $\begin{array}{c}-0.122 \\
(0.108)\end{array}$ & $\begin{array}{c}0.068 \\
(0.100)\end{array}$ \\
\hline Performance & $\begin{array}{c}0.046 * * * \\
(0.015)\end{array}$ & $\begin{array}{c}0.043 * * * \\
(0.016)\end{array}$ & $\begin{array}{c}0.046 * * * \\
(0.017)\end{array}$ & $\begin{array}{c}0.046 * * * \\
(0.017)\end{array}$ & $\begin{array}{c}0.004 \\
(0.019)\end{array}$ \\
\hline Baseline RMSSD & & $\begin{array}{c}0.000 \\
(0.003)\end{array}$ & & $\begin{array}{c}0.000 \\
(0.003)\end{array}$ & $\begin{array}{l}-0.001 \\
(0.002)\end{array}$ \\
\hline RMSSD change & & & $\begin{array}{c}0.003 \\
(0.003)\end{array}$ & $\begin{array}{c}0.003 \\
(0.003)\end{array}$ & $\begin{array}{c}0.002 \\
(0.003)\end{array}$ \\
\hline Confidence & & & & & $\begin{array}{c}-0.216 * * * \\
(0.055)\end{array}$ \\
\hline Risk attitude & & & & & $\begin{array}{c}0.071^{* * * *} \\
(0.017)\end{array}$ \\
\hline Competition attitude & & & & & $\begin{array}{l}-0.009 \\
(0.017)\end{array}$ \\
\hline Performance change & & & & & $\begin{array}{l}-0.142 \\
(0.098)\end{array}$ \\
\hline Observations & 80 & 77 & 77 & 77 & 77 \\
\hline Pseudo $\mathrm{R}^{2}$ & 0.090 & 0.078 & 0.084 & 0.084 & 0.336 \\
\hline Correctly classified (\%) & 65.00 & 63.64 & 66.23 & 67.53 & 71.43 \\
\hline
\end{tabular}

Table reports average marginal effects with standard errors in parentheses. Woman is a dummy variable, where women $=1$ and men $=0$. Performance denotes the number of correctly solved arithmetic problems in Task 2 . RMSSD change denotes competition-induced change in heart rate variability measured in normalized RMSSD values. Confidence denotes participants' guesses about their rank among the group members in Task 2 and takes values from 1 to 4, where lower values indicate higher self-confidence. Risk attitude denotes participants' answer to a general risk question on a scale from 1 to 10 where lower values indicate lower willingness to take risks. Competition attitude denotes participants' answer to a general competition attitude question on a scale from 1 to 10 where lower values indicate lower willingness to compete. Performance change denotes the difference in the number of correctly solved arithmetic problems between Tasks 2 and 1. Positive values indicate greater performance in the tournament compensation scheme than in the piece rate. $* * *$ significant at $\mathrm{p}<0.01$, ** significant at $\mathrm{p}<0.05, *$ significant at $\mathrm{p}<0.1$. 
Table S7: Probit models on Task-3 payment scheme choice for low performers

$(1=$ tournament, $0=$ piece rate $)$

\begin{tabular}{|c|c|c|c|c|c|}
\hline & (1) & (2) & (3) & (4) & $(5)$ \\
\hline \multirow[t]{2}{*}{ Woman } & -0.186 & -0.245 & -0.143 & -0.232 & $-0.166^{*}$ \\
\hline & $(0.147)$ & $(0.159)$ & $(0.150)$ & $(0.157)$ & $(0.100)$ \\
\hline \multirow[t]{2}{*}{ Performance } & $0.079 * *$ & $0.078 * *$ & $0.072 *$ & $0.073 * *$ & 0.051 \\
\hline & $(0.037)$ & $(0.036)$ & $(0.038)$ & $(0.036)$ & (0.039) \\
\hline \multirow[t]{2}{*}{ Baseline RMSSD } & & 0.005 & & 0.006 & $0.006^{* *}$ \\
\hline & & $(0.006)$ & & $(0.004)$ & $(0.003)$ \\
\hline \multirow[t]{2}{*}{ RMSSD change } & & & -0.007 & -0.007 & -0.0004 \\
\hline & & & $(0.006)$ & $(0.005)$ & $(0.003)$ \\
\hline \multirow[t]{2}{*}{ Confidence } & & & & & $-0.304 * * *$ \\
\hline & & & & & $(0.050)$ \\
\hline \multirow[t]{2}{*}{ Risk attitude } & & & & & $0.035 * *$ \\
\hline & & & & & $(0.024)$ \\
\hline \multirow[t]{2}{*}{ Competition attitude } & & & & & -0.035 \\
\hline & & & & & $(0.024)$ \\
\hline \multirow[t]{2}{*}{ Performance change } & & & & & $-0.213 *$ \\
\hline & & & & & $(0.108)$ \\
\hline Observations & 36 & 35 & 35 & 35 & 35 \\
\hline Pseudo $\mathrm{R}^{2}$ & 0.095 & 0.116 & 0.115 & 0.147 & 0.631 \\
\hline Correctly classified (\%) & 66.67 & 71.43 & 60.00 & 62.86 & 94.29 \\
\hline
\end{tabular}

Table presents average marginal effects with standard errors in parentheses. Woman is a dummy variable, where women $=1$ and men $=0$. Performance denotes the number of correctly solved arithmetic problems in Task 2 . RMSSD change denotes competition-induced change in heart rate variability measured in normalized RMSSD values. Confidence denotes participants' guesses about their rank among the group members in Task 2 and takes values from 1 to 4 , where lower values indicate higher self-confidence. Risk attitude denotes participants' answer to a general risk question on a scale from 1 to 10 where lower values indicate lower willingness to take risks. Competition attitude denotes participants' answer to a general competition attitude question on a scale from 1 to 10 where lower values indicate lower willingness to compete. Performance change denotes the difference in the number of correctly solved arithmetic problems between Tasks 2 and 1. Positive values indicate greater performance in the tournament compensation scheme than in the piece rate. ${ }^{* * *}$ significant at $\mathrm{p}<0.01,{ }^{* *}$ significant at $\mathrm{p}<0.05$, * significant at $\mathrm{p}<$ 0.1 . 
Table S8: Pairwise correlation coefficients, all participants

\begin{tabular}{|l|c|c|c|c|c|c|c|c|}
\hline & $\begin{array}{c}\text { Willingness } \\
\text { to compete }\end{array}$ & Performance & $\begin{array}{c}\text { Baseline } \\
\text { RMSSD }\end{array}$ & $\begin{array}{c}\text { RMSSD } \\
\text { change }\end{array}$ & Confidence & Risk attitude & $\begin{array}{c}\text { Competition } \\
\text { attitude }\end{array}$ & $\begin{array}{c}\text { Performance } \\
\text { change }\end{array}$ \\
\hline $\begin{array}{l}\text { Willingness } \\
\text { to compete }\end{array}$ & 1.000 & & & & & & \\
\hline Performance & $0.345^{* * *}$ & 1.000 & -0.125 & 1.000 & & & & \\
\hline $\begin{array}{l}\text { Baseline } \\
\text { RMSSD }\end{array}$ & 0.156 & $-0.233^{* *}$ & 0.073 & 1.000 & & & \\
\hline $\begin{array}{l}\text { RMSSD } \\
\text { change }\end{array}$ & $-0.295^{* * *}$ & $-0.522^{* * *}$ & 0.0905 & 0.117 & 1.000 & & \\
\hline $\begin{array}{l}\text { Confidence } \\
\text { Risk attitude }\end{array}$ & $-0.512^{* * *}$ & $0.360^{* * *}$ & 0.049 & 0.001 & -0.011 & -0.110 & 1.000 & 1.000 \\
\hline $\begin{array}{l}\text { Competition } \\
\text { attitude }\end{array}$ & $0.220^{*}$ & 0.110 & $-0.206^{*}$ & -0.067 & $-0.265^{* *}$ & $0.287 * *$ & 1.000 \\
\hline $\begin{array}{l}\text { Performance } \\
\text { change }\end{array}$ & -0.060 & $0.313^{* * *}$ & 0.100 & -0.073 & $-0.188^{*}$ & $-0.227^{* *}$ & -0.177 \\
\hline
\end{tabular}

$* * *$ significant at $\mathrm{p}<0.01, * *$ significant at $\mathrm{p}<0.05, *$ significant at $\mathrm{p}<0.1$

Table S9: Pairwise correlations coefficients, all men

\begin{tabular}{|c|c|c|c|c|c|c|c|c|}
\hline & $\begin{array}{l}\text { Willingness } \\
\text { to compete }\end{array}$ & Performance & $\begin{array}{l}\text { Baseline } \\
\text { RMSSD }\end{array}$ & $\begin{array}{l}\text { RMSSD } \\
\text { change }\end{array}$ & Confidence & Risk attitude & $\begin{array}{l}\text { Competition } \\
\text { attitude }\end{array}$ & $\begin{array}{l}\text { Performance } \\
\text { change }\end{array}$ \\
\hline $\begin{array}{l}\text { Willingness } \\
\text { to compete }\end{array}$ & 1.000 & & & & & & & \\
\hline Performance & $0.507 * * *$ & 1.000 & & & & & & \\
\hline $\begin{array}{l}\text { Baseline } \\
\text { RMSSD }\end{array}$ & 0.015 & -0.037 & 1.000 & & & & & \\
\hline $\begin{array}{l}\text { RMSSD } \\
\text { change }\end{array}$ & $-0.441 * * *$ & -0.183 & -0.261 & 1.000 & & & & \\
\hline Confidence & $-0.636 * * *$ & $-0.635 * * *$ & -0.061 & $0.287 *$ & 1.000 & & & \\
\hline Risk attitude & -0.156 & -0.033 & -0.159 & 0.032 & 0.176 & 1.000 & & \\
\hline $\begin{array}{l}\text { Competition } \\
\text { attitude }\end{array}$ & 0.162 & 0.170 & -0.061 & -0.113 & -0.197 & $0.298^{*}$ & 1.000 & \\
\hline $\begin{array}{l}\text { Performance } \\
\text { change }\end{array}$ & 0.019 & $0.403 * *$ & 0.199 & 0.034 & $-0.271^{*}$ & -0.184 & -0.212 & 1.000 \\
\hline
\end{tabular}

*** significant at $\mathrm{p}<0.01, * *$ significant at $\mathrm{p}<0.05, *$ significant at $\mathrm{p}<0.1$ 
Table S10: Pairwise correlation coefficients, all women

\begin{tabular}{|c|c|c|c|c|c|c|c|c|}
\hline & $\begin{array}{l}\text { Willingness } \\
\text { to compete }\end{array}$ & Performance & $\begin{array}{l}\text { Baseline } \\
\text { RMSSD }\end{array}$ & $\begin{array}{l}\text { RMSSD } \\
\text { change }\end{array}$ & Confidence & Risk attitude & $\begin{array}{c}\text { Competition } \\
\text { attitude }\end{array}$ & $\begin{array}{l}\text { Performance } \\
\text { change }\end{array}$ \\
\hline $\begin{array}{l}\text { Willingness } \\
\text { to compete }\end{array}$ & 1.000 & & & & & & & \\
\hline Performance & 0.157 & 1.000 & & & & & & \\
\hline $\begin{array}{l}\text { Baseline } \\
\text { RMSSD }\end{array}$ & $0.323 * *$ & -0.209 & 1.000 & & & & & \\
\hline $\begin{array}{l}\text { RMSSD } \\
\text { change }\end{array}$ & -0.197 & $-0.323 * *$ & 0.205 & 1.000 & & & & \\
\hline Confidence & $-0.359 * *$ & $-0.320 * *$ & 0.132 & -0.044 & 1.000 & & & \\
\hline Risk attitude & $0.679 * * *$ & 0.136 & 0.125 & -0.031 & $-0.344 * *$ & 1.000 & & \\
\hline $\begin{array}{l}\text { Competition } \\
\text { attitude }\end{array}$ & 0.240 & 0.021 & -0.263 & -0.030 & $-0.322 * *$ & $0.264 *$ & 1.000 & \\
\hline $\begin{array}{l}\text { Performance } \\
\text { change }\end{array}$ & -0.072 & 0.208 & -0.015 & -0.182 & -0.157 & -0.240 & -0.119 & 1.000 \\
\hline
\end{tabular}

$* * *$ significant at $\mathrm{p}<0.01, * *$ significant at $\mathrm{p}<0.05, *$ significant at $\mathrm{p}<0.1$

\section{References:}

Fischbacher, U. (2007). z-Tree: Zurich toolbox for ready-made economic experiments. Experimental economics, 10(2), 171-178.

Niederle M. \& Vesterlund L. (2007). Do women shy away from competition? Do men compete too much? The Quarterly Journal of Economics, 122 (3), 1067-1101.

Parak, J., \& Korhonen, I. (2013). Accuracy of Firstbeat Bodyguard 2 beat-to-beat heart rate monitor. White paper by Firstbeat Technologies Ltd. 


\section{Experimental instructions}

\section{General information}

You will participate in a study which is conducted by the Aalto University and the Joint Research Centre of the European Commission. Your responses will be strictly confidential, meaning that your name will never be associated with your test results. Please read the instructions carefully. Please do not communicate with other participants during the experiment. If you have any questions, please, raise your hand. We will answer your question personally.

We will measure your heart rate variability during the experiment. After reading these instructions, you have to install the heart rate monitor you will find on your desk. The device is attached to the skin with two sticky electrodes. The other end is attached to the right side, below the collarbone, and the other end to the left side, to the costal arch (see the instructions next to the device). After you have installed the heart rate monitor, you should sit still and avoid unnecessary movements. The device saves heart rate and motion data. We will use later this data in our analysis.

During the experiment, you will be asked to answer questions, for example, about your risk attitude, your life situation and your personal background. Please answer those questions carefully, as your answers are of utmost importance when analyzing the results of the experiment. The actual experimental task will consist of several different tasks. You will get separate instructions prior to each task.

At the end of the experiment, we will pay you 5 euros for participation. In addition, you can earn more during the experiment. Your earnings will depend on your own choices as well as on the decisions of other participants during the experiment. The experiment consists of five different tasks and there is always a break between the tasks. Each task will take up to five minutes. At the end of the experiment, one of the five pay-off relevant tasks will be selected at random. This randomly selected task will determine your pay-off from the experiment. Since your earnings will be determined on the basis of a randomly selected task, it is in your best interest to pay special attention to all the tasks assigned to you. Your earnings are differently determined in different tasks. In total, the experiment lasts about an hour. You can drop out of the experiment at any point for any reason. 
In summary, your total earnings in this experiment consist of 5 Euro participation fee, a pay-off related with a randomly selected task, and a pay-off related with one background questionnaire. At the end of the experiment, your earnings will be paid to you in private.

Thank you for your participation!

\section{Practice task}

Before the start of the actual experiment, you can familiarize yourself with the experimental procedures and practice the use of the computer. In the following, the computer will display five randomly selected two-digit numbers. Your task is to calculate the sum of these numbers. During this practice period, you have two minutes to calculate the correct sum of as many series of numbers as possible.

You are not allowed to use a calculator or any other electronic devices to solve the problems. We have placed a pen and scratch paper in your cubicle. You can use the pen and paper at your own discretion. You submit your answers using your computer mouse and keyboard. You will have to enter your answer in the box at the end of each line. When you have answered, you will get the next five numbers. Your answers to the problems are anonymous. No other participant will see your answers at any stage. Your performance during the practice task does not affect your final payment. Once you have understood the instruction click CONTINUE on the computer screen. The task begins once all subjects are ready.

\section{Task [Piece rate payment]}

The computer will display five randomly selected two-digit numbers. Your task is to calculate the sum of the numbers. You have five minutes to calculate the correct sum of as many series of numbers as possible.

You are not allowed to use a calculator or any other electronic devices to solve the problems. We have placed a pen and scratch paper in your cubicle. You can use these devices at your own discretion. You submit your answers using your computer mouse and keyboard. You will have to enter your answer in 
the box at the end of each line. When you have answered, you will get the next five numbers. Your answers to the problems are anonymous. No other participant will see your answers at any stage.

If this task is the one randomly selected for payment at the end of the experiment, you will earn 25 cents of every problem you solved correctly. Wrong answers do not lower the payment. We refer to this payment scheme as the piece rate payment.

Once you have understood the instruction click CONTINUE on the computer screen. The task begins when all subjects are ready.

\section{Task [Tournament payment]}

The computer will display five randomly selected two-digit numbers. Your task is to calculate the sum of the numbers. You have five minutes to calculate the correct sum of as many series of numbers as possible.

You are not allowed to use a calculator or any other electronic devices to solve the problems. We have placed a pen and scratch paper in your cubicle. You can use these devices at your own discretion. You submit your answers using your computer mouse and keyboard. You will have to enter your answer in the box at the end of each line. When you have answered, you will get the next five numbers. Your answers to the problems are anonymous. No other participant will see your answers at any stage.

During the task, you will belong to a group of four. The members in each group are randomly selected so that each group includes both men and women. If this period is selected for the payment at the end of the experiment, your pay-off is based on your performance in comparison with the other group members. The individual, who correctly solves the largest number of problems, will earn 100 cents for every problem he/she solved correctly. Wrong answers do not lower the payment. The other group members do not earn anything. In the event of a tie, the winner will be randomly determined. You will not be informed about your rank until the very end of the experiment. We refer to this payment scheme as the tournament payment.

Once you have understood the instruction click CONTINUE on the computer screen. The task begins once all subjects are ready. 


\section{Task [Own choice]}

As in the previous tasks, the computer will display five randomly selected two-digit numbers. Your task is to calculate the sum of the numbers. You have five minutes to calculate the correct sum of as many series of numbers as possible.

You are not allowed to use a calculator or any other electronic devices to solve the problems. We have placed a pen and scratch paper in your cubicle. You can use these devices at your own discretion. You submit your answers using your computer mouse and keyboard. You will have to enter your answer in the box at the end of each line. When you have answered, you will get the next five numbers. Your answers to the problems are anonymous. No other participant will see your answers at any stage.

In contrast to the previous tasks, you can now choose between the two previous payment schemes. If this task is the one randomly selected for payment at the end of the experiment, your earnings are determined as follows:

a) If you choose the piece rate payment, you will earn 25 cents of every problem you solved correctly. Wrong answers do not lower your payment.

b) If you choose the tournament payment, your earnings are based on your performance in comparison to the members of the same group as in the previous task (Task 2 - Tournament payment). If you choose the tournament payment and correctly solve more problems than the other members of your group solved during the Task 2, you will earn 100 cents for each problem you solved correctly. Wrong answers do not lower the payment. If you choose the tournament payment, but you do not manage to correctly solve more problems than the best of the other members in your group during the Period 2, you will not earn anything. In the event of a tie, the winner will be randomly determined.

You can indicate the desired payment scheme by selecting the scheme on your computer screen.

Once you have understood the instructions and selected the desired payment scheme click CONTINUE on the computer screen. The task begins when all subjects are ready. 


\section{Task [New choice]}

In this task, you do not have to add numbers. Instead, you can reconsider the Task 1 (Piece rate payment). Your task is to choose the payment scheme you want to be applied to your performance in the Task 1 . You can choose either the piece rate or the tournament payment.

If this task is the one randomly selected for payment at the end of the experiment, your earnings are determined as follows:

a) If you choose the piece rate payment, you will earn 25 cents of every problem you solved correctly in the Task 1 . Wrong answers do not lower the payment.

b) If you choose the tournament payment, and you correctly solved more problems than the other members or your group solved during the Task1, you will earn 100 cents for each problem you solved correctly. The group is the same as in the Tasks 2 and 3 . Wrong answers do not lower the payment. If you choose the tournament payment, but you did not manage to solve correctly more problems than the best of the other members of your group solved during the Task 1, you will not earn anything. In the event of a tie, the winner will be randomly determined.

On the computer screen, you are now told how many problems you solved correctly during the Task 1 , and you are requested to indicate your desired payment scheme.

Once you have understood the instruction click CONTINUE on the computer screen. The task begins once all subjects are ready. 


\section{Risk elicitation}

Below are listed a variety of risky lotteries. On each row there are two options, A and B. For example, in the first A-option, you can win 2 euro with probability of $1 / 10$ and 1.60 euro with probability of $9 / 10$, while in the first B-option, you can win 3.85 euro with probability $1 / 10$ and 0.10 euro with probability of 9/10. Mark in every row below which of the option do you prefer, A or B. After you have filled out the form we will randomly select one row and either option A or B. You will be paid based on your choice and the random draw.

\begin{tabular}{|c|c|c|c|c|c|c|c|c|}
\hline \multicolumn{4}{|c|}{ Option A } & \multicolumn{4}{|c|}{ Option B } & A or B? \\
\hline $1 / 10$ & of $2.00 €$ & $9 / 10$ & of $1.60 €$ & $1 / 10$ & of $3.85 €$ & $9 / 10$ & of $0.10 €$ & \\
\hline $2 / 10$ & of $2.00 €$ & $8 / 10$ & of $1.60 €$ & $2 / 10$ & of $3.85 €$ & $8 / 10$ & of $0.10 €$ & \\
\hline $3 / 10$ & of $2.00 €$ & $7 / 10$ & of $1.60 €$ & $3 / 10$ & of $3.85 €$ & $7 / 10$ & of $0.10 €$ & \\
\hline $4 / 10$ & of $2.00 €$ & $6 / 10$ & of $1.60 €$ & $4 / 10$ & of $3.85 €$ & $6 / 10$ & of $0.10 €$ & \\
\hline $5 / 10$ & of $2.00 €$ & $5 / 10$ & of $1.60 €$ & $5 / 10$ & of $3.85 €$ & $5 / 10$ & of $0.10 €$ & \\
\hline $6 / 10$ & of $2.00 €$ & $4 / 10$ & of $1.60 €$ & $6 / 10$ & of $3.85 €$ & $4 / 10$ & of $0.10 €$ & \\
\hline $7 / 10$ & of $2.00 €$ & $3 / 10$ & of $1.60 €$ & $7 / 10$ & of $3.85 €$ & $3 / 10$ & of $0.10 €$ & \\
\hline $8 / 10$ & of $2.00 €$ & $2 / 10$ & of $1.60 €$ & $8 / 10$ & of $3.85 €$ & $2 / 10$ & of $0.10 €$ & \\
\hline $9 / 10$ & of $2.00 €$ & $1 / 10$ & of $1.60 €$ & $9 / 10$ & of $3.85 €$ & $1 / 10$ & of $0.10 €$ & \\
\hline $10 / 10$ & of $2.00 €$ & $0 / 10$ & of $1.60 €$ & $10 / 10$ & of $3.85 €$ & $0 / 10$ & of $0.10 €$ & \\
\hline
\end{tabular}

